\title{
Estado, Movimiento, Pueblo. La triple articulación de la Unidad Política ${ }^{1,2 y 3}$ Carl Schmitt
}

\section{Presentación de la traducción}

\author{
Joseba Miren García Celada \\ Ministerio de Empleo y Seguridad Social \\ josebagarc@gmail.com
}

Recibido / received: 27/11/2016

Aceptado / accepted: 23/03/2017

\section{DOI: https://doi.org/10.20318/eunomia.2017.3668}

El contundente título de la obra parece más disuasorio que atractivo pero, si no se renuncia a avanzar en la lectura del texto, podrá descubrirse que comporta interesantes puntos de reflexión, de un jurista de indudable capacidad, en un contexto histórico de grandes cambios, por desgracia no muy lejano de situaciones actuales, esperemos que no paralelas, por lo que a menudo puede encontrarse el lector con cuestiones que le lleven a murmurar "me suena el tema".

Animamos al lector a leer estas páginas, pues "las certezas se conquistan con ansias de dudas, no con profesiones de fe que evitan ese tormento" (Volpe, 2000: 327). Schmitt aparece aquí como el respaldo doctrinal del régimen nacionalsocialista en toda su crudeza, sin ambages, rompiendo la imagen de figura del positivismo jurídico, al que critica duramente e incluso denostando el pretendido

\footnotetext{
${ }^{1}$ Texto original de Carl Schmitt, Staat, Bewegung, Volk. Die Dreigliederung der politischen Einheit, Hamburg: Hanseatische Verlagsanstalt, 1933.

${ }^{2}$ La traducción, partiendo de las versiones italianas, corresponde a Joseba Miren García Celada, miembro del Cuerpo Superior de Administradores Civiles del Estado y Subdirector General de Tecnologías de la Información y Comunicaciones del Ministerio de Empleo y Seguridad Social. La revisión de la traducción, partiendo del texto en alemán, corresponde a Miguel Ángel Cobos Gómez de Linares, Profesor Titular de Derecho penal de la Universidad Complutense de Madrid.

${ }^{3}$ Nota del Traductor: El subtítulo ha planteado posibles diferentes versiones, desde "los tres pilares..." a "la división tripartita de la unidad política". El término "Gliederung" admite diversas posibles traducciones: articulación, clasificación, división, estructura... Hemos realizado la opción escogida por entender que es la mejor expresión del pensamiento de Schmitt.
} 
cientifismo de los iuspositivistas.

Los años 20 marcaron en Europa una búsqueda de respuestas a un profundo cuestionamiento de la democracia parlamentaria en un contexto de crisis económica generalizada, en Europa y en Estados Unidos. Ante una acrecentada desigualdad social, los pueblos no perciben la respuesta urgente que millones de personas, sufrientes y desmoralizadas, esperan de la democracia parlamentaria, de la forma de representación democrática constituida como paradigma de la liberaldemocracia pero que se presenta, a veces interesadamente, dominada y dedicada a luchas partidarias y de reparto de espacios de poder.

A partir de la contraposición de la legitimidad de la soberanía popular, de su expresión a través de representantes sin mandato frente a la considerada la auténtica voluntad del pueblo, se plantean alternativas, que hoy denominaríamos populistas, antisistema: una izquierda revolucionaria, con el referente de la reciente revolución soviética (aunque aún sin la imposición de la homogenización estalinista) y una derecha, también revolucionaria pero en otro sentido. En común, la promesa de que se dará solución a la grave situación social y a los desmanes de una economía liberal sin frenos a la que se considera culpable de esa situación, pero por lo demás enemigos acérrimos e irreconciliables del pueblo y del Estado, pues la ideología y la organización partidaria pasan a identificarse con el pueblo y el propio Estado.

Schmitt construye para el nacionalsocialismo una legitimidad que afirma el principio de autoridad, la sacralización de la unidad y la jerarquización total de las estructuras estatales y sociales, puesto que el estado pasa a abarcarlo todo, es el Estado total. Pero esa legitimidad se apoya en una visión de la soberanía del pueblo que se contrapone al parlamentarismo, entendido como la voluntad de los pertenecientes a la "estirpe", puesto que los demás son ajenos al pueblo alemán. Ante la consideración de la ineficiencia endémica que se achaca al parlamentarismo, se propone un sistema plebiscitario, tanto porque el Führer puede plantear consultas sobre cuestiones concretas, como porque las elecciones (eso sí, de cargos del único partido) pasan a ser un plebiscito que respalda la acción del partido ${ }^{4}$. Pasamos de la política basada en el individuo a la sociedad de masas, que se libera de las rémoras del respeto de los derechos atribuidos a ese individuo (contrapuestos al Estado) para alcanzar su politización total (Leibholz, 1993: 85).

Frente a las calificadas como estériles luchas partidarias y la lentitud e ineficiencia del Parlamento se da todo el poder a los órganos ejecutivos. Considera Schmitt que no se puede dar pie a que participen (ni siquiera se tomen en consideración sus opiniones o propuestas ideológicas) los enemigos del Estado, los que pretenden destruirlo (comunistas e ideologías ajenas a la "estirpe alemana" en general), los derechos individuales constitucionalizados son un punto de vulnerabilidad del Estado que sólo sirve para ser explotado por quienes quieren destruirlo, de forma similar, las competencias territoriales y el concepto de federalismo, son la base para la disgregación de la unidad nacional y para impedir el funcionamiento eficaz de la administración.

La cuestión de la autoridad y el arbitraje por encima de partidos y

\footnotetext{
${ }^{4}$ Ésta es de hecho la tendencia genérica para todos los sistemas políticos, «cuando los partidos son débiles y el sector privado también, las organizaciones públicas y semipúblicas se vuelven las fuentes naturales de reclutamiento». Jean Blondel, "Government Ministers in the Contemporary World", Londres, Sage, 1985, pág. 62.
} 
parlamento, no es un descubrimiento de las ideologías fascistas, ya estaba en planteamientos dentro de la propia república de Weimar, el propio Schmitt en El Guardián de la constitución (1931) participa en el debate proponiendo el papel neutral del presidente del Reich y, más claramente, está en la idea del Tribunal Constitucional de Kelsen.

El debate es sobre la legitimidad de la democracia parlamentaria y la participación del soberano, del pueblo no entendido como entelequia roussoniana sino como entidad de seres vivos de la nación, la participación en las decisiones se plantea recurrentemente ante las crisis del sistema liberaldemocrático, especialmente cuando se percibe por amplios sectores de la población un divorcio entre los intereses de la clase política, de los representantes del soberano, y las apremiantes cuestiones que precisan solución desde el punto de vista de una sociedad que siente que las instituciones son lentas, cuando no insensibles, a esas necesidades. Las cuestiones de eficacia y eficiencia de las instituciones, de legitimidad de los representantes en cuanto su actuación ha de reflejar las necesidades de los representados, las vías de la democracia participativa y los peligros de los sistemas plebiscitarios, pero también de secuestro de la voluntad soberana y, por tanto, de la democracia como tal, se mantienen abiertas hoy en día y siguen exigiendo una evolución de las instituciones ${ }^{5}$. Para la ideología nacionalsocialista la unidad no es igualdad, se reivindica el tratamiento diferente de lo que se considera distinto, pues además de la exclusión de los ajenos a la estirpe y a lo que se considera el genuino pensamiento alemán, se reivindican las jurisdicciones especiales de todo tipo y las formas corporativas rayanas incluso con el gremialismo.

Hay una mistificación nada científica, la estirpe alemana, el pensamiento genuinamente alemán, la misión inmanente del partido=movimiento, sostén de Estado y pueblo, valores por tanto trascendentes y transversales a lo largo de la historia, que se considera han sobrevivido a la ideología liberaldemocrática, por supuesto calificada como ajena al pensamiento alemán, y que se reconectan más con la monarquía absoluta que con la democracia heredera de la Revolución Francesa. No hay referencias religiosas en la invocación de esos valores trascendentes; al contrario cierta desconfianza del papel que puedan jugar las iglesias, tal vez anunciando incluso el intento, la tentación, poco después mostrada, de crear una mística nazi.

En todo caso, el planteamiento para la creación de un sistema jurídico y su legitimación para el nacionalsocialismo, no nace espontáneamente desde la nada, sino que se plantea por sus propios "juristas" como la evolución del sistema político y jurídico que corresponde al siglo XX, la superación moderna de los viejos modelos del siglo XIX. El autoritarismo prusiano se alaba repetidamente, pero se considera insuficiente por lo limitado de su control del Estado y la sociedad; es el paso del "Estado autoritario" al "Estado total" lo que se propone, ya lo encontramos teorizado

\footnotetext{
${ }^{5}$ Véase M. Hart y A. Negri "Imperio", Harvard University Press, Cambridge, Massachussets, 2000, págs. 79 y ss. http://www.ddooss.org/articulos/textos/lmperio Negri Hardt.pdf. Muy interesante en esta línea el debate bien reciente entre Eugenio Scalfari y Gustavo Zagrebelsky, donde el primero defiende que la democracia sólo puede ser una oligarquía (http://www.repubblica.it/politica/2016/10/13/news/perche difendo I oligarchia-149655377/) frente a la defensa de Zagrebelsky del referéndum como forma de participación democrática que, entre otras, ha de permitir una mayor identificación del pueblo con la democracia (http://www.repubblica.it/politica/2016/10/12/news/zagrebelsky risponde a scalfari oggi su repubblica-149584896/?ref=HRER2-1)
} 
antes incluso que en Schmitt en muchos autores de la época, en los años 20 y 30 del siglo XIX: Leibholz (1993, 87), Forsthoff, Ziegler... También la Constitución de Weimar es invocada, si bien, en un ejercicio que tiene algo de prestidigitación, se considera una base para explicar cómo se llega legítimamente al acceso al poder de los nazis, pero se rechaza que pueda ser invocada por juristas y tribunales para impugnar o siquiera criticar, las actuaciones del nuevo poder constituyente, no en el sentido clásico, sino a través de instrumentos normativos diversos puesto que la competencia legislativa no está limitada como exclusiva del Parlamento.

La teorización de Schmitt nos pone sobre aviso de los peligros de no dar respuesta, desde la propia democracia, al distanciamiento e incluso desafecto entre las instituciones y el Derecho que las rige y el pueblo soberano y sus necesidades y sentimientos socialmente extendidos, y cómo las tentaciones autoritarias, como el refuerzo de la legislación por decreto en aras de la aparentemente más eficaz acción frente a la lentitud del debate parlamentario o el gobierno fuerte y con autoridad, precisamente si consiguen transmitir la sensación de éxito pretendida, son fáciles argumentos para avanzar hacia el "Estado total".

Finalmente, hay que señalar que la traducción ha tomado como base las versiones italianas del mismo, publicadas en 1935 por Delio Cantimori y en 2005 por Giorgio Agamben ${ }^{6}$ y se han contrastado con el texto original de Schmitt publicado en 1933, correspondiendo esta última labor al profesor Miguel Ángel Cobos Gómez de Linares. La recargada y a veces oscurantista redacción viene del estilo imperante en la época, especialmente en medios jurídicos. El texto italiano de 1935 introduce cambios respecto del original no sólo derivados de las opciones lingüísticas de la acción traductora, sino también derivadas de la ideología del autor que señala diferencias de enfoque entre la ideología nacionalsocialista y la fascista: el pueblo de la versión alemana se convierte en nación, los sindicatos se traducen por ligas, lo que podría traducirse del alemán como gremios se convierten en corporaciones, etc.

El término Führer lo hemos traducido por Jefe. Si bien tal vez la traducción literal podría llevarnos a considerar más ajustado el uso de "Guía", creemos que expresa mejor el significado de lo que en esta obra se teoriza el término que efectivamente se utilizaba como traducción en castellano en los años 30. Recuérdese, sin ir más lejos, la importación del lema "todo el poder para el Jefe" que utilizó la CEDA en su campaña electoral o el uso del término "Jefe" (y mando) que también hizo la Falange, bebiendo de fuentes sobre todo italianas, pero también alemanas. De hecho la traducción italiana de 1935 utiliza el término "capo", equivalente a jefe, mientras que la de 2005 opta por "guía" (guida).

Otro término/concepto sobre el que hemos reflexionado es el de superintendencia. Sus sentidos, según el Diccionario de la RAE son: "1. f. Suprema administración en un ramo. 2. f. Empleo, cargo y jurisdicción del superintendente". 3. f. Oficina del superintendente". Es un término de escaso uso en el castellano en España, pero es un concepto de Derecho administrativo de más tradición en otros países y más usado en Latinoamérica. La alternativa, el concepto de supervisión, no llena completamente el significado del término, por lo pronto porque no tiene reflejo en la denominación de órganos administrativos que, en cambio, sí se definen como "superintendencia" de o para algo. Por lo dicho hemos mantenido el término en sí para que refleje lo que Carl Schmitt argumenta.

\footnotetext{
6 "Stato, Movimento, Popolo. Le tre membra dell'unitá política", en "Un giurista davanti a sè stesso. Saggi e interviste", por G. Agamben, Neri Pozza, Vicenza, 2005, págs. 255-312. "Principi politici del nacionalsocialismo", por D. Cantimori, 1935, pags. 173-231.
} 


\section{Bibliografía}

VOLPE, G. (2000), II constitucionalismo del Novecento, Laterza, Bari.

BLONDEL, J. (1985), Goverment Ministers in the Contemporary World, Sage, Londres.

LEIBHOLZ, G. (1993), La dissoluzione della democracia limerale in Germania e la forma di Stato autoritaria; Giufrè, Milán.

HART, M. y NEGRI, A. (2000), Imperio, Harvard University Press, Cambridge. 


\section{ESTADO, MOVIMIENTO, PUEBLO La triple articulación de la Unidad Política Carl Schmitt}

\section{La situación constitucional actual.-}

1. Todo el Derecho público del Estado alemán actual se apoya sobre un terreno propiamente suyo. Disposiciones concretas de la Constitución de Weimar están aún en vigor, pero no cabe decir lo mismo de la gran masa de las disposiciones prerrevolucionarias, por tanto sólo lo están en la medida que no contradigan la nueva situación jurídica, y no como base o legitimación del Estado actual. La continuidad de su validez se basa en una asunción en parte tácita y en parte expresa (por ejemplo en lo que se ha mantenido, de lo que enseguida hablaremos, de la Constitución provisional - de la llamada Ley de Plenos Poderes - de 24 de marzo de 1933) por el nuevo Derecho público. La Constitución de Weimar no podría, ni por su contenido material, ni formalmente por su vigencia legal como Constitución, ser la base de un Estado nacionalsocialista.

La Constitución de Weimar ya no está en vigor. Todos los principios y medidas que por la parte ideal y por la parte organizativa resultaban esenciales para esta Constitución han sido apartados junto con todos sus precedentes. Incluso antes de la llamada Ley de Plenos Poderes de 24 de marzo de 1933, un Decreto del Presidente del Reich de 12 de marzo de 1933 ha derogado solemnemente o suprimido junto con la bandera en negro-rojooro del sistema de Weimar (art. 3 de la Constitución de Weimar), su espíritu y su base. Tampoco para la aniquilación del enemigo del Estado y del pueblo, del partido comunista, se podía estar esperando la autorización de un sistema que por su propia debilidad y neutralidad no era capaz ni siquiera de identificar a un enemigo mortal del pueblo alemán. Una medida jurídica como la Ley del Reich Contra la Formación de Nuevos Partidos de 14 de julio de 1933 (RGBL. ${ }^{7}$ I, pag. 479) y la Ley para la Garantía de la Paz Legal de 13 de octubre de 1933 (RGBL. I, pag. 723) niega desde su raíz tanto ideológicamente ${ }^{8}$ como en sus consecuencias organizativas, la Constitución de Weimar. Ésta no se identifica ya consigo misma cuando todo el mundo ideal liberaldemócrata ha caído, cuando por ejemplo no hay ya formación de

\footnotetext{
${ }^{7}$ Nota del Traductor: Diario Oficial del Reich, hoy Diario Oficial Federal (Bundesgesetzblatt)

${ }^{8}$ Nota del Traductor: utiliza el término "weltanschaulich", literalmente "visión del mundo", con un sentido más amplio que la ideología aunque este último término sí aparece más adelante.
} 
partidos, libertad política de propaganda, de opinión, de conciencia y de actividad para tendencias adversas al Estado, cuando se ha terminado la neutralidad ideológica, que llegaba hasta el suicidio, la igualdad o sea la no diferenciación entre enemigo del Estado y amigo del Estado, entre connacional y extraño a la estirpe ${ }^{9}$. El nuevo mundo del Derecho nacionalsocialista no puede de ninguna manera comprenderse, y mucho menos justificarse o basarse en conceptos y formas de la Constitución de Weimar. Todo intento de justificar o de refutar la actual situación jurídica en base a la Constitución de Weimar es por tanto, visto desde el Estado nacionalsocialista, o un juego sin sentido, o una expresión de una tendencia política para reconducir el Derecho público válido actualmente o la auctoritas rei constitutae que corresponde al actual Estado, al orden de ideas de otro tiempo y así paralizarlo o por lo menos relativizarlo.

También desde el punto de vista de la denominada validez formal de la ley constitucional, las disposiciones de la Constitución de Weimar decaen. La Constitución provisional de 24 de marzo de 1933 (la denominada Ley de Plenos Poderes) como también la Ley sobre el Plebiscito de 14 de julio de 1933 (RGBL. I, pag. 479) superan los límites de toda norma imaginable a partir de la Constitución de Weimar. Lo que se ha conservado en la Constitución provisional de 24 de marzo de 1933 (derechos del Presidente del Reich, además de la Dieta del Reich [Reichstag] y el Consejo del Reich como instituciones) no tiene valor ante aquella Ley Sobre el Plebiscito de 14 de julio de 1933. Con la ayuda de esta ley pueden por tanto hacerse leyes que vayan más allá de lo que se ha preservado en la Constitución provisional de 24 de marzo de 1933.

Varios juristas, que obviamente no pueden acostumbrarse a la realidad del Estado nacionalsocialista, han intentado presentar algunas nuevas leyes fundamentales de este Estado como desviaciones de la Constitución de Weimar, desviaciones que habrían de medirse exclusivamente en función de la denominada "Ley de Plenos Poderes"; mirándolas entonces según los casos o, magnánimamente, como "admisibles" o, críticamente, como "inadmisibles". Esta es una concepción insostenible internamente, insostenible absolutamente. No se puede considerar el texto de la Constitución de Weimar como un Derecho que siga siendo válido ahora y ulteriormente bajo el nuevo Derecho público y constitucional del Estado nacionalsocialista; de lo que habría entonces que deducir que el Derecho público nacionalsocialista ( $¡$ como las leyes de 1924 para el plan Dawes! ${ }^{10}$ ) sirva sólo como medida intermedia y transitoria sobre el fondo de la

\footnotetext{
${ }^{9}$ Nota del Traductor: Schmitt utiliza el término "Artfremd", a traducir por "ajenos a la especie", aunque el traductor italiano ha utilizado "stirpe". No es una referencia a la denominada "raza aria”, que parece reservarse para los mítines y la acción, no para el campo jurídico.

${ }^{10}$ Nota del Traductor: Se refiere al Informe que un comité, bajo la presidencia del financiero norteamericano Charles Dawes, presentó - el 9 de abril de 1924. Basándose en el principio de "negocios, no política", el Plan Dawes recomendaba la reorganización del Reichsbank alemán bajo supervisión aliada. Los pagos de reparaciones, por valor de un billón de marcos-oro, se efectuarían anualmente, aumentando al final de un período de cinco años hasta alcanzar la cifra de dos billones quinientos mil marcos-oro. Alemania recibiría, y aquí estaba la clave del plan, un crédito extranjero por valor de 800 millones de marcos-oro. El 16 de abril, el gobierno alemán aceptó el Plan y en una Conferencia reunida en Londres en julio-agosto de 1924 se adoptó definitivamente el Plan Dawes. http://www.historiasiglo20.org/GLOS/plandawes.htm
} 
Constitución precedente, y que una simple ley de la Dieta del Reich podría abolir de nuevo todo el nuevo Derecho constitucional y llevar de vuelta a la Constitución de Weimar ${ }^{11}$. ¿Cómo puede diferenciarse el "mero" texto de una Constitución de su contenido y de su validez formal, y cómo es posible decir con lógica jurídica que por su contenido sí es válido un nuevo Derecho constitucional, con validez plena, y que el contenido del Derecho constitucional de Weimar no está ya en vigor, pero que no obstante sigue en vigor un texto de la Constitución de Weimar que carece de validez sólo momentáneamente ? $^{12}$ Hago mención a este punto de vista sólo para dar un ejemplo de la confusión que enseguida se presenta si se abandona el punto de vista, claro y simple, de que el Derecho del actual Estado nacionalsocialista no está fundado sobre una base esencialmente extraña y adversa, sino sobre una propia.

¿Pero qué significa entonces la Ley del Reich de 24 de marzo de 1933, que también fue votada en la forma de una ley transformadora de la Constitución $^{13}$, con la requerida mayoría de dos tercios, conforme a las disposiciones del artículo 76 de la Constitución de Weimar? Esta denominada Ley de Plenos Poderes ha sido decidida por la Dieta del Reich sólo como ejecución de la voluntad popular manifestada en las elecciones de la Dieta de 5 de marzo de 1933. Las elecciones han sido en realidad, consideradas con criterios de la ciencia jurídica, un referéndum popular, un plebiscito, con el que el pueblo alemán ha reconocido a Adolf Hitler, Jefe (Führer) del Movimiento nacionalsocialista, como Jefe (Führer) político del pueblo alemán. Las elecciones municipales de 12 de marzo han confirmado una vez más la misma voluntad popular. Pero para los hábitos mentales del denominado jurista positivista que han durado hasta hoy se presenta no obstante como algo natural encontrar en esta ley la base jurídica del Estado actual. La expresión "Ley de Plenos Poderes"14 (Ermächtigungsgesetz) refuerza aún más la tendencia a este error. Es por tanto necesario reconocer en la palabra Ermächtigungsgesetz una denominación jurídicamente imprecisa, es más, errada; y sería oportuno evitar totalmente la palabra, tanto más cuando no aparece ni en el título de la ley (Gesetz zur Behebung der Not von Volk und Reich ${ }^{15}$ ) ni en el texto, y sólo se ha adherido externamente a la ley. En realidad esta "Ley de Plenos Poderes" es una Ley Constitucional

${ }^{11}$ Así p.e. MEDICUS en el Deutsches Recht de Pfundtner-Neubert, Berlín, 1933, "Nota a la Ley del Reich de 24 de marzo de 1933", y SCHEUNER, Leipziger Zeitschrift, agosto 1933 (p.903).

${ }^{12}$ Nota del Traductor: esta enrevesada redacción se corresponde, en el original alemán, con una larga pregunta sin puntuación.

${ }^{13}$ Esta interpretación la he mantenido inmediatamente después de la publicación de la Ley (por primera vez el 21 de marzo de 1933 en la sesión de la Sociedad Alemana para el Progreso de la Ciencia Política en Weimar). Parece que entre tanto se ha impuesto. Por ello asume un especial significado que el Secretario de Estado de Interior del Reich, el Dr. Pfundtner (conferencia en la Academia Administrativa de Berlín de 4 de julio de 1933, fase 1 de la Administración Pública en el Nuevo Reich, 1933), haya adoptado el mismo punto de vista y haya denominado a la Ley "Constitución provisional".

${ }^{14}$ Nota del Traductor: Esta ley es conocida como "Ley de Plenos Poderes", pero la expresión alemana "Ermächtigungsgesetz" debería traducirse como "Ley de Apoderamiento", lo que permitiría entender mejor la digresión de Schmitt al criticar la denominación otorgada a la norma frente al título real de la misma.

${ }^{15}$ Nota del Traductor: -- El título alemán de la Ley viene a ser "Ley Para la Erradicación de la Miseria del Pueblo y del Reich". 
provisional de la nueva Alemania.

La Constitución provisional del 24 de marzo de 1933 tiene todas las características de una medida de transición. Si es correcta, según la Constitución de Weimar, en forma de ley transformadora de la Constitución de acuerdo con el artículo 76, ello no significa que se pueda considerar todavía hoy que la Constitución de Weimar sea la base del Estado actual, sino que significa únicamente que esa ley representa un puente entre el Estado viejo y el nuevo, desde la vieja base hasta la nueva base. Fue de gran importancia práctica que esta transición se produjese legalmente. Dado que, como se recordará también más abajo, la legalidad es una forma de funcionamiento del aparato estatal de funcionarios y autoridades, y por ello tiene importancia política y jurídicamente. Y no carece tampoco de valor que un sistema se rinda por sí solo con todas las reglas, conforme a su propia legalidad, y ponga su sello en su propio fin. Pero esto es sólo la abdicación y la autodeclaración de defunción del viejo Derecho, y no una determinación de la esencia del nuevo. Ni la base, ni el límite, ni ningún punto de vista de interpretación esencial, que pueda atar al Estado actual, puede deducirse de la vieja época, que se ha despedido. Para el Derecho ahora en vigor esa Ermächtigung del 24 de marzo de 1933 no es otra cosa que una especie de analogía republicana de aquella expresa exoneración del juramento de fidelidad que pronuncia un monarca al renunciar al trono o abdicar. Esa legalización, en cuanto a su sentido político-jurídico, es al nuevo Derecho lo que la mentalidad legalista de un Estado liberaldemocrático es al principio de lealtad de un Estado de funcionarios monárquico.

La revolución alemana fue legal, es decir formalmente correcta según la Constitución de antes. Lo fue por disciplina y por el sentido alemán del orden. Por lo demás su legalidad significa una propiedad que se determina solamente con base en la anterior Constitución de Weimar, por tanto con base en un sistema superado. Sería jurídicamente falso y políticamente una acción de sabotaje deducir de esta especie de legalidad una ulterior validez de ideas jurídicas, instituciones o normas ya superadas, y con ello una sumisión permanente a la letra o al espíritu de la Constitución de Weimar. El buen Derecho de la revolución alemana no se fundamenta en el hecho de que unas docenas de diputados estuviesen dispuestos a cubrir con su aprobación la diferencia del quince por cien que hay entre la mayoría simple y la mayoría de dos tercios, y el Derecho de Estado alemán actual no está ligado a los precedentes, a las restricciones o incluso a las reservas mentales con las que ese grupo ha aportado su concurso. Sería absurdo tanto políticamente como moral y jurídicamente, dar plenos poderes con base en la falta de poder, y de esta forma apropiarse de nuevo del poder un sistema devenido impotente. Lo que está vivo no puede legitimarse con lo que está muerto, y la fuerza no necesita legitimarse con la debilidad.

Rudolf Hess, el representante de nuestro Jefe (Führer), ha dicho en el congreso del partido de 1933, en Núremberg, que aquel congreso del partido era un "parlamento" (Reichstag) ${ }^{16}$ del tercer Reich, y esto es dar en el blanco; pero el concepto de "parlamento" no se regula ya como la institución del mismo nombre tal y como se entiende en la Constitución de Weimar. Y cuando el representante del Jefe (Führer) pronuncia la frase: "Todo el poder

\footnotetext{
${ }^{16}$ Nota del Traductor: En realidad en el original alemán hay un juego de palabras entre "Parteitag" y "Reichstag".
} 
procede del pueblo", esto es algo esencialmente distinto que cuando la Constitución liberaldemócrata de Weimar usa las mismas palabras en su art. 1. Todo nuestro Derecho público, incluidas todas las disposiciones retomadas de la Constitución de Weimar y válidas posteriormente, están sobre una base completamente nueva. Los trazos fundamentales de la nueva estructura estatal serán expuestos más abajo (II). Aquí sólo debe dejarse claro desde un principio, frente a todas las falsas construcciones jurídicas que querrían al Estado nacionalsocialista en el carril y en las formas de pensar del antiguo y superado pensamiento público, cuál es el Derecho propio de nuestro nuevo Estado.

2. Las disposiciones constitucionales hoy válidas incluyen la coexistencia de muchos cargos supremos del Reich así como también de muchas posibilidades de legislación.

a) Como cargos supremos del Reich hay que citar hoy: el Presidente del Reich, el Canciller del Reich, el Consejo del Reich ${ }^{17}$. La cuestión de la relación recíproca entre los diversos cargos supremos no se puede resolver con base en la Constitución de Weimar. Para el reagrupamiento ${ }^{18}$ de los cargos supremos del Reich sirve como criterio ordenador que el Canciller del Reich es el Jefe (Führer) político del pueblo alemán que está políticamente unido en el Reich alemán. Esta preeminencia de la dirección política es una ley fundamental del Derecho público actual. Los derechos del Presidente del Reich permanecen a salvo. Pero la situación anormal de los últimos años del sistema de Weimar, en la que el Presidente del Reich estaba obligado a salir de la naturaleza propia de su alta función y a hacer de subrogado de una dirección (Führung) política, hoy ha desaparecido. Él está ahora de nuevo en una especie de posición "constitucional" de Jefe de Estado autoritario qui regne et ne gouverne pas. Se sobrentiende hoy, no sólo de facto sino en un pleno sentido de iure, que el Canciller del Reich Adolf

${ }^{17}$ El Consejo Económico del Reich y el representante del Presidente del Reich pueden dejarse aparte. El Consejo Económico del Reich, no obstante la Ley de 5 de abril de 1933 (RGBL. I, pag. 165), es una formación transitoria con un significado poco claro, hasta que no se decida su destino mediante la construcción de una Constitución social de categorías profesionales (corporaciones). Por lo que se refiere a la representación del Presidente del Reich, y según la Ley sobre la Representación del Presidente del Reich de 17 de diciembre de 1932 (RGBL. I, pag. 547), en cualquier caso de incapacidad, incluso la más breve, del Presidente del Reich, debe representarle no el Canciller del Reich, sino el Presidente del Tribunal del Reich. Esta medida, como es conocido, se ha adoptado en un momento especialmente turbio del Estado -de-muchos-partidos de Weimar. Su sentido y finalidad están ahí, que en tal sistema pluralista los partidos en lucha entre ellos no tienen ninguna voluntad política unitaria, sino que se pueden encontrar como mucho en un punto político cero. En el Estado nacionalsocialista, que se fundamenta en el principio del jefe (Führerprinzip), una disposición nacida por tales razones se convierte en absurda. Por ello la Ley de 17 de diciembre de 1932, desde mi punto de vista, aunque sin una abolición expresa, ha perdido ya toda validez, como otras disposiciones constitucionales del sistema de Weimar que no se corresponden ya con el Derecho actual. Si se tuviese que considerar necesaria una derogación especial de esta Ley, no resultaría tal vez superfluo, por razones psicológicas, en nuestro periodo de transición, pero no es en modo alguno imprescindible ni constitucional ni jurídicamente.

${ }^{18}$ Nota del Traductor-. Schmitt utiliza el término "Gruppierung", agrupamiento, sólo cabe interpretar que se refiere a que ha de evitarse la dispersión o dilución de los cargos - como apunta lo que sigue a continuación. 
Hitler tiene según el Derecho estatal una posición que no es comparable con la posición de ningún Canciller precedente, sea respecto del Presidente del Reich, sea ante los miembros del gobierno del Reich. La "dirección" política de Adolf Hitler es también algo más y diferente que una simple "determinación de directivas" según el artículo 56 de la Constitución de Weimar. La situación jurídica ha cambiado tras la muerte de Hindenburg; pero la esencia política no ha cambiado.

b) Además de la coexistencia de estos cargos coexisten también diversas posibilidades legislativas. La vía legislativa hoy normal es la de una decisión del gobierno del Reich (art. 1 de la Constitución provisional de 24 de marzo de 1933). Junto a esto el gobierno del Reich tiene la posibilidad de consultar al pueblo por la vía del voto, y precisamente sobre medidas y leyes (Ley de 14 de julio de 1933). Las posibilidades legislativas de la Constitución de Weimar (decisión de la Dieta del Reich según el art. 68 y plebiscito según el art. 73) siguen igualmente abiertas. Finalmente también el derecho del Presidente del Reich de promulgar decretos, que representan leyes del Reich, según el art. 48 párrafo 2 , está todavía en vigor y en casos concretos ha sido ejercido.

Ante a estas múltiples posibilidades legislativas se plantea también el problema de su ordenación jerárquica y sus relaciones recíprocas. Tampoco en esta cuestión se puede decidir con interpretaciones formalistas y sofistas de las palabras con base en la Constitución de Weimar. El Derecho público del Estado nacionalsocialista debe más bien ser consciente de que la prioridad absoluta de la dirección política es una ley fundamental del Estado actual positivamente en vigor. Forma parte de la aplicación consecuente de esta ley fundamental que la separación liberal-constitucional del legislativo y del ejecutivo decaiga, y que el gobierno tenga una auténtica y formal capacidad legislativa (como por lo demás se reconoce en el art. 1 de la Constitución provisional de 24 de marzo de 1933) o que además toda iniciativa legislativa sea por principio cosa del gobierno. En consecuencia hay todavía una petición del Jefe (Führer) a la Dieta del Reich, y por esta vía pueden presentarse supuestos de legislación del Reich: pero se suprime en cambio no sólo de hecho sino también de derecho toda posibilidad de convocar a la Dieta del Reich contra la voluntad del Jefe (Führer) (supongamos que en base al pretendido derecho de un tercio de los miembros, según el art. 24) o de presentar allí una denominada ley de iniciativa. También el plebiscito y la iniciativa legislativa popular de la Constitución de Weimar decaen ante el nuevo derecho de consulta popular del gobierno del Reich.

La ulterior cuestión de la relación entre una ley del gobierno del Reich y una ley hecha mediante consulta popular se puede decidir igualmente sobre la base de reconocidos principios nacionalsocialistas. El gobierno del Reich reconoce como decisiva la voluntad del pueblo, al que ha interpelado, y se considera por tanto vinculado a ella. De ninguna forma se adjudica el derecho de abolir simplemente con una nueva ley de gobierno una ley del Reich hecha con base en una consulta popular. Otra cosa es que dada una situación de hecho que ha cambiado totalmente la ley popular no tenga ya cabida en absoluto y pierda su significado. Entonces le correspondería a la dirección política decidir de qué manera 
debe adoptarse una nueva y necesaria medida y cuál de las posibilidades que para ello tenga a su disposición - nueva consulta popular, nueva formación de la Dieta, decisión de la Dieta, ley de gobierno - debe utilizar.

Las nuevas elecciones para la Dieta del Reich, que con un Decreto del Presidente del Reich de 14 de octubre de 1933 (RGBI. I, pag. 729) fueron convocadas para el 12 de noviembre de 1933, deben entenderse sólo como parte integrante del gran plebiscito de ese mismo día, con el que el pueblo alemán debe tomar posición ante la política de gobierno del Reich y pronunciarse. Ya en el sistema de Weimar las denominadas elecciones habían perdido desde hacía tiempo su auténtico carácter de elecciones; se habían convertido, como se ha constatado repetidamente, en una opción plebiscitaria de las masas electoras entre cinco o seis programas e ideologías incompatibles, opciones que erosionaban al pueblo alemán con otros tantos partidos incompatibles. En el Estado de un solo partido de la Alemania nacionalsocialista el peligro de tal laceración pluralista de la Alemania de los muchos partidos políticos ha sido superado. Las elecciones se convierten así en una respuesta del pueblo a un llamamiento lanzado por la dirección (Führung) política. El carácter de llamamiento de la nueva formación de la Dieta del Reich y su conexión con el plebiscito se han mostrado de forma indiscutible el 12 de noviembre.

II

\section{LA TRIPLE ARTICULACIÓN DE LA UNIDAD POLÍTICA}

1. La unidad política del Estado actual es la unión de tres articulaciones: Estado, movimiento, pueblo. Se diferencia radicalmente del esquema estatal liberaldemócrata que nos llegó desde el siglo XIX, y no sólo por sus presupuestos ideológicos y sus principios generales, sino también en todas las líneas esenciales de la construcción y la organización del concreto edificio del Estado. Cada concepto esencial y cada institución se ve afectada por esta diversidad.

La nueva construcción estatal está marcada por el hecho de que la unidad política del Pueblo y por tanto todo el ordenamiento de su vida pública aparecen ordenados en tres series distintas. Las tres series no discurren paralelas una a otra, sino que una de ellas, el movimiento, que sostiene al Estado y al Pueblo, penetra y dirige a las otras dos. Tres cables o vías ordenadoras discurren una junto a la otra, cada una organizada en sí misma, se encuentran en ciertos puntos decisivos, especialmente en la cumbre, tienen contactos recíprocos y conexiones transversales de un determinado tipo pero que no suprimen sus diferencias, y forman en su conjunto, unificado por la serie ordenadora que sostiene el todo, la estructura de la unidad política. Cada uno está conformado en sí mismo según diversos puntos de vista, y, si se puede decir de esta manera, con diferente material, pero todos, aunque de forma diferente, están ligados por el ordenamiento jurídico público.

Cada una de las tres palabras: Estado, Movimiento, Pueblo, puede usarse por sí sola para la totalidad de la unidad política. Pero designa al mismo tiempo también un lado particular y un elemento específico de esta totalidad. Así puede considerarse al Estado en sentido estricto como 
la parte política estática, al movimiento como el elemento político dinámico y al pueblo como el lado apolítico que crece bajo la protección y a la sombra de las decisiones políticas. Sin embargo sería falso extraer de ello, de forma sofista, contraposiciones que separan - y recíprocamente excluyen, y hacer jugar a Estado contra Movimiento y Movimiento contra Estado, a Pueblo contra Estado y Estado contra Pueblo, a Pueblo contra Movimiento y Movimiento contra Pueblo. Esto se correspondería con las separaciones liberales que trataremos de nuevo más abajo, cuyo sentido político es la anulación $o$ al menos la relativización de la totalidad política. Especialmente el movimiento es tanto Estado como pueblo, y ni el Estado actual (en el sentido de unidad política) ni el pueblo alemán actual (el sujeto de la unidad política "Reich alemán") serían imaginables sin el movimiento.

De esto resultan las tres series ordenadoras siguientes:

a) El aparato estatal de las autoridades y de las oficinas, que consiste en el ejército y los funcionarios estatales; viene siendo designado todavía a menudo (según un uso lingüístico tradicional) como el Estado, pero sólo es tal como organización de mando, de administración y de justicia, por tanto sólo en el sentido más estricto, mientras que la palabra "Estado" en el sentido más amplio se utiliza siempre, como se ha dicho, como la designación tradicional de la totalidad de la unidad política de un pueblo;

b) Un partido que sostiene al Estado y al pueblo, reclutado entre todos los estratos del pueblo pero cerrado en sí mismo y dirigido jerárquicamente, porque requiere una construcción especialmente severa y una dirección rígida; partido que es el cuerpo político en el que el movimiento encuentra su particular forma. Ha sido designado por los sociólogos como "orden", "élite", o de forma parecida, para diferenciarlo del partido político del Estado liberal (que por principio no está organizado de una forma fija, sino que se basa en la "propaganda libre"). Pero aquí podemos mantener todavía la habitual denominación de "partido", dado que hoy no cabe temer un malentendido al respecto. Esto responde también a lo recogido en la ley de 14 de julio de 1933 (RGBI., I, p.479) contra las nuevas constituciones de partidos: "En Alemania existe un único partido político, el Partido Nacionalsocialista Alemán de los Trabajadores";

c) Una esfera del pueblo dejada a una administración autónoma, que abarca tanto al ordenamiento económico y social como a las categorías profesionales y también a la administración autónoma municipal (basada en el vecindario local). También un Estado corporativo del Estado fascista (Korporationstaat des faschistischen Staates), que rechaza por principio una administración autónoma territorial y admite únicamente administraciones autónomas técnicas o "funcionales", o un sistema de sindicatos y ligas, un ordenamiento social popular (esta palabra ha sido acuñada por Werner Sombart: (Volkstümliche Sozialordnung) que podrían ocupar esta esfera de la administración autónoma no estatal pero de Derecho público, e introducir en la vida política del pueblo una autonomía que sería 
posible en el marco general de la dirección política, y un corporativismo o también uniones federadas de diverso tipo.

En el Estado del movimiento nacionalsocialista alemán se puede reconocer como en el Estado fascista de Italia, aunque de forma muy diferente, este nuevo triple encuadre del conjunto de la unidad política. Es en general típico del Estado del siglo XX. También en el Estado bolchevique de la unión de los Soviets se ha intentado una construcción con tres partes, Estado, partido y sindicato como elementos inclusivos de la realidad política y social. La construcción con tres partes no sólo es visible por doquier allí donde se tratan de superar los ciegos vínculos del sistema liberaldemocrático y construir un Estado nuevo conforme a la realidad social y política del siglo XX; se corresponde también con la gran tradición, fundada por Hegel, de la doctrina estatal alemana. Sólo en la segunda mitad del siglo XIX ha sido expulsada a la fuerza de la conciencia del pueblo alemán por la influencia de teóricos y escritores liberales y extraños a nuestra estirpe. Esta construcción triforme debería ser por tanto plausible universalmente como primera consecuencia de la actual estructura estatal; ésta no se ve afectada en modo alguno por la objeción de que se trate sólo de una idealización de situaciones italianofascistas.

Es además en sí misma una cuestión de construcción y organización, con base en qué relación las tres series ordenadoras, y las series organizativas pertenecientes a las anteriores, se correspondan recíprocamente la una con la otra; y así también es una cuestión de ciencia jurídica y estatal la relación recíproca entre las tres subestructuras correspondientes. Pero en la denominación "partido que sostiene a Estado y pueblo" ya se dice que la dirección política se debe apoyar en esta serie ordenadora, y que por tanto los otros dos órdenes son superados por esta segunda organización (que en nuestra construcción está en medio), y son penetrados por ella, dirigidos, y conformados de forma decisiva. El partido políticamente dirigente sostiene, como organización del "movimiento", tanto al "aparato estatal", como al ordenamiento social y económico, como a la totalidad de la unidad política. De esto resulta el significado central del concepto jurídico, que ya se ha citado varias veces y que se ha de desarrollar todavía más en detalle, de dirección política.

Dicho en abstracto o genéricamente, la relación recíproca de las tres series ordenadoras en diversas unidades políticas y en distintas épocas puede ser muy diferente. Para el Estado hegeliano de funcionarios de estirpe prusiano-alemana - que fue la realidad histórica aproximadamente de 1815 a 1848, bajo la monarquía ya limitada, tras el puro absolutismo y antes del reconocimiento constitucional de los cuerpos legislativos burgués-parlamentarios - era por ejemplo característico que una clase de funcionarios estatales, espiritual y moralmente elevada, e incorruptible, ejerciese también las funciones de grupo sostenedor del Estado, mientras que en otros Estados la clase de los funcionarios se entendía solamente como instrumento burocrático de los sostenedores del Estado. Dentro de la serie organizadora estatal puede luego presentarse nuevamente, por ejemplo, la ulterior cuestión de la relación entre estatalidad civil y militar, entre poder gubernamental y poder de mando. Y se forman también por influencia recíproca, dirección o dominio, múltiples métodos, que se gestionan a veces públicamente y de forma visible, otras veces internamente y de forma invisible, otras con 
base en normas determinadas previamente, otras libremente según la situación de las cosas y la oportunidad, y que se desarrollan en instituciones de diverso tipo. El seguimiento de este problema sería la tarea para una precisa "teoría del Estado" del siglo XX. No digo: de una "teoría general del Estado"; porque la categoría de teoría "general" del Estado es, como ha visto Pablo Ritterbusch, un asunto típico del liberal siglo XIX; nace de la tendencia normativista por resolver el Estado concreto y el pueblo concreto en una "generalidad" (cultura general, teoría jurídica general, al final teoría gnoseológica general), y destruir así su esencia política.

2. Hay que volver a recordar siempre que tanto el concepto de "Estado" como el de "pueblo" son transformados por esta triplicidad, y que la forma tradicional de teorizar ${ }^{19}$, surgida de la situación histórica del siglo XIX, no puede ya alcanzar a la nueva realidad. El Estado, en el sentido de la clase estatal de los funcionarios y de las autoridades pierde el monopolio de la política que había adquirido en los siglos XVII y XVIII. Es reconocido como una simple parte de la unidad política, y precisamente una parte basada sobre la organización que sostiene al Estado. El conjunto de las autoridades y los funcionarios por sí solo no se identifica ya por tanto con la totalidad política ni con una autoridad de "superiores" que se apoya sobre sí misma. Hoy ya no se puede determinar la política partiendo del Estado, sino que hace falta que el Estado sea determinado partiendo de la política. Pero también la Constitución estatal elaborada, del siglo XIX en adelante, por este "Estado", y la legalidad que de ella se deduce, se desplazan consiguientemente desde el centro de la colectividad a otro lugar de la vida política. Cuanto más se formaliza y mecaniza la legalidad, tanto más manifiestamente entra en contradicción con el Derecho, que permanece siendo bueno en su contenido; aquélla recibe el significado secundario que le corresponde, relativo por ser instrumental; se convierte en el modo de funcionamiento del aparato estatal de las autoridades. Esta legalidad se parece tan poco al Derecho del pueblo como el aparato estatal a la unidad política del pueblo. Al Derecho en el sentido sustancial le corresponde en primer lugar asegurar la unidad política; sólo sobre la base de decisiones políticas incontestables, y desde este sentido positivo, puede explicarse el Derecho en todos los campos de la vida pública que crece libre y autónomamente.

La teoría del Estado y del Derecho de la última y de la penúltima generación de juristas ha percibido esta oposición entre Derecho y legalidad estatal - que respondía a la absoluta incongruencia entre la unidad del pueblo y el aparato estatal de las autoridades - y lo ha expresado sosteniendo por un lado que por "ley" se entendiese "toda norma jurídica" y por otra parte formalizando y mecanizando al mismo tiempo el Derecho como ley y la ley de nuevo como resolución de la mayoría del cuerpo legislativo, o sea del parlamento. No se hace referencia aquí tanto a la conocida diferencia entre Derecho del pueblo y Derecho de los juristas, (Volksrecht, Juristenrecht) cuanto al enconamiento conceptual abstracto de la oposición en la teoría "general"

${ }^{19}$ Nota del Traductor: el término utilizado en el texto es "imaginar". 
entre Derecho y Estado. Una doctrina interesante por su lógica interna consideraba solamente al funcionario, es decir a la justicia y a la administración como aplicadoras de la ley, y no al "ciudadano" como el auténtico destinatario de la norma legal; podía por tanto considerar al final el Derecho, en general, sólo como "el conjunto de las reglas de la actuación estatal". Lo dice una cita, que es especialmente característica de esta forma de pensar liberal-constitucional (y junto con su relación con la lengua alemana): "20 "También las propuestas de Derecho (en sentido estricto) que establecen deberes jurídicos de los súbditos y norman pena y ejecución, tienen por contenido, en referencia a la actividad ejecutiva de castigar y de ejecutar, a realizar mediante los órganos estatales, la administración estatal" (KELSEN, Haupt-probleme der Staatsrechtslehre, p. 252). Todo Derecho se convierte así en un sentido particular en "Derecho estatal", y viceversa, toda actividad estatal en "Derecho", es decir ejecución de norma por parte del aparato estatal de las autoridades, sujeto a normas. Esto no tiene ya nada que ver con Derecho o Justicia en sentido positivo y sustancial, pero es típico del sistema político de las despolitizaciones liberales. El normativismo liberal aparenta aquí un "dominio de la norma legal" que en realidad es sólo el dominio de un sistema de legalidad, dominado por fuerzas no estatales y políticamente irresponsables, por encima del aparato de las autoridades. Esta forma de pensar positivista y "funcionalista", que niega toda sustancia del Derecho, conoce además el "Derecho" sólo como un vínculo calculable del aparato coercitivo estatal, es decir como modo de funcionamiento de las autoridades y las jerarquías competentes. Pero junto a esto seguía subsistiendo en la praxis jurídica, como ya se ha dicho, el llamado concepto material de la ley; la ley era "norma legal", y toda norma legal, también el Derecho consuetudinario, era "ley"; ésta se dirigía (a diferencia del simple decreto administrativo) no sólo al "funcionario" (sujeto por una especial relación de fuerza), sino también al "ciudadano" (sujeto solamente por la fuerza estatal "general"). Había entonces por tanto dos representaciones del Derecho y de la ley (representaciones de diverso tipo y sin conexión entre sí), dos destinatarios de las normas, dos concepciones de la ley y por tanto dos especies de Derecho que se anulan entre sí.

En la construcción en tres partes de la unidad política los conceptos de "Estado" y de "pueblo" tienen otra posición y un sentido bien diferente que en el sistema de dos partes de la democracia liberal (ver más abajo, III). El modo de pensar con dos partes opera también aquí con separaciones antitéticas, como Estado contra pueblo y pueblo contra Estado, gobierno contra pueblo y pueblo contra gobierno. En el Estado nacionalsocialista el cuerpo político dirigente que sostiene al Estado y al pueblo tiene la tarea de impedir y superar todas las antítesis de este tipo. El pueblo por tanto no es ya una simple suma de electores no gobernantes. El funcionario estatal no está ya, como en el Estado constitucional monárquico, contrapuesto al ciudadano llamado "libre", cuya libertad es esencialmente aestatalidad y un concepto polémico liberal dirigido contra el "no libre" soldado o funcionario de carrera. La clase de los funcionarios estatales ya ni siquiera está constreñida, como en el sistema de partidos pluralistas de 1919 a 1932, a tener que organizarse como un grupo de interés y a identificarse, en vez de con la

\footnotetext{
${ }^{20}$ Kelsen utiliza palabras de origen alemán como statuieren (Nota del Traductor al italiano)
} 
idea y la institución del funcionario alemán, con "unos derechos bien adquiridos", construidos individualmente, en cada funcionario. El funcionario es ahora un compatriota (Volksgenosse) en una unidad política basada en la igualdad de la estirpe, es como un compañero de partido, un miembro de la organización que conduce a Estado y pueblo, y ésta está ocupada, en los puestos decisivos de mando (Umschaltstellen) del organismo estatal de las autoridades, por jefes políticos del movimiento que conduce a Estado y pueblo.

Correlativamente, también la esfera de la administración autónoma popular y de las categorías profesionales resulta penetrada por el movimiento; aunque de una forma que - a diferencia del organismo de la clase de los funcionarios y de las autoridades, relativamente despolitizado solo por su carácter estatal, - aquí se reconoce como una esfera de formaciones autónomas despolitizada en un grado superior. Pero esta "despolitización" no tiene nada que ver con el abuso político que se hacía antes con los pretendidos asuntos "apolíticos" de la administración autónoma, sino que depende totalmente de la decisión política de la dirección política reconocida. Constituye un conocimiento fundamental de la generación alemana actual que precisamente decidir si un asunto o un tipo de cosas son apolíticos es en sí una decisión específicamente política. Tanto la "objetividad" del funcionario, en particular la "independencia" de los jueces, como el carácter apolítico de la esfera popular de administración autónoma son posibles con todas las ventajas y las seguridades de lo apolítico sólo si ambos se someten a la dirección política y a las decisiones políticas del movimiento que sostiene al Estado y al pueblo. Éste es por tanto en su sentido específico el elemento político de la colectividad, un motor dinámico frente al elemento estático que resulta ser el aparato de las autoridades, que está sujeto a las normas y a las decisiones políticas implícitas en ellas, y así mismo garante político de la despolitizada administración autónoma, municipal o de grupos profesionales, $-{ }^{21}$

3. Del conjunto de la nueva estructura resulta la nueva regulación de las relaciones entre el Reich y los Estados regionales (Länder). La ley sobre el Delegado ${ }^{22}$ del Reich de 7 de abril de 1933 ha garantizado la prioridad de la dirección política del Reich frente a las regiones y ha sometido a los Länder a la dirección política de jefes subordinados al ReichsFührer. Tanto el concepto tradicional de Estado federal monárquico-dinástico del siglo XIX como el pluralista Estado federal de partidos surgido en la debilidad interna y la corrupción del sistema Weimar han sido así superados. Se puede decir con una fórmula corta y sintetizadora de Derecho estatal que la conjunción de la idea federal con la idea estatal sea bajo la forma de la federación de Estados, sea bajo la forma de

\footnotetext{
${ }^{21}$ La cuestión de a qué serie de esta construcción en tres partes pertenecen las iglesias, sigue dejándose aparte. Hasta que la iglesia no levanta ninguna pretensión política totalitaria, ésta puede encontrar su puesto en la tercera esfera, es decir en la esfera de la administración autónoma; no si la iglesia levanta la pretensión política de totalidad, lo que significa que ella pretenda asignar su puesto a Estado, movimiento y pueblo, y quiera distinguir entre amigo y enemigo del pueblo con sus propios criterios.

${ }^{22}$ Nota del Traductor: se ajustaría más al texto italiano "lugarteniente", pero el sentido de la norma y la versión alemana nos llevan a preferir "delegado".
} 
Estado federal - fue durante un siglo el auténtico peligro para la unidad política de Alemania. Dado que en toda organización federal se presupone una garantía del status quo territorial y político, ésta debe, tanto en una federación de Estados como en un Estado federal, aprovechar el carácter estatal de cada Estado-miembro como una unidad política en sí, y de esta forma convierte en relativa la unidad estatal de todo el pueblo alemán. Por tanto no sólo en una federación de Estados, sino también en un Estado federal, no le resulta difícil a un hábil abogadillo construir, en caso de conflicto, invocando la "base federal" o la "esencia y concepto" del Estado federal, un "derecho a una política propia". Los teoremas y las arengas del proceso de Leipzig, de los gobiernos prusiano y bávaro Braun-Severing-Hirtsiefer y Held, y la sentencia del Tribunal Estatal ${ }^{23}$ de 25 de octubre de 1932, contienen bonitos ejemplos y documentos de tales "infinitas cláusulas del federalismo". ${ }^{24}$ Sólo sobre el trasfondo de este mundo prenacionalsocialista de ideas del Estado federal de partidos, aparece con su auténtico significado el valor de la ley sobre los lugartenientes del Reich, que hoy en el rápido proceso de desarrollo de la unidad alemana podría tal vez parecer superada.

Después de esta ley ya no es posible denominar a los Länder como Estados, a menos que se transforme esencialmente una vez más, como después de 1781, el concepto de "Estado". Se podría intentar tal vez, para salvar a los Länder como Estados, quitar al concepto de Estado, al que a partir de 1871 se le había quitado la característica de la soberanía, la característica de lo "político" o "despolitizar" totalmente a las regionesEstado. En sí no resultaría impensable, dado lo conocido de las palabras y los conceptos, designarlos como "Estados" regionales o provincias, como de hecho la unidad política de los "Estados Unidos de América" consiste en "Estados". La expresión "Estado" significaría entonces solamente una especial independencia en las articulaciones o una especial descentralización dentro de una unidad política. Pero hoy es más importante dejar fuera de toda duda que las articulaciones territoriales dentro del Reich están sometidas sin condiciones y sin reservas a la dirección política del Reich, y que no pueden pretender un "derecho a una política propia" bajo ningún travestismo; sobre todo no con el pretexto hasta ahora extremadamente peligroso del "carácter político" de un asunto. Para nuestras concepciones alemanas actuales la idea de un "Estado despolitizado" es tan imposible como lo sería la de un "ejército desmilitarizado". Los Länder alemanes sí tienen competencias que pertenecen a un "poder estatal"; tienen por tanto poder estatal; pero en ningún caso son "Estados". Estado alemán lo es sólo el Reich alemán. El Reich es una formación articulada, compuesta por Länder o provincias ampliamente independientes, pero no un "Estado federal". Este funesto concepto del siglo XIX, que conceptualmente fija conjuntamente federación y Estado y hace así del Reich un no-Estado, debe desaparecer del Derecho interno alemán. Si debe conservarse la palabra "federalismo", es una cuestión puramente práctica de terminología,

\footnotetext{
${ }^{23}$ Nota del Traductor: se refiere a la Sala del Tribunal Constitucional de la República de Weimar para disputas territoriales.

${ }^{24}$ Así el Comisario del Reich para la justicia ministro de Estado Doctor Frank en el congreso del partido del Reich de 1933 (Juristische Wochenschrift, 1933, p. 2091)
} 
Mientras subsista el peligro de que con base en los hábitos tradicionales del pensamiento del Ochocientos, federalismo o Estado federal sean puestos a la par, debería ser mejor evitar esta palabra de la que se ha abusado. No olvidamos lo que se ha dicho en el Mein Kampf de Adolf Hitler sobre el "federalismo como máscara".

El desarrollo que se ha iniciado con la ley sobre los lugartenientes del Reich de 7 de abril de 1933 no ha terminado aún. Las declaraciones del Jefe (Führer) al congreso del partido de este año en Núremberg son conocidas (1933). La unidad política del pueblo alemán no se fundamenta en las regiones o en las estirpes alemanas ${ }^{25}$, sino en la unidad cerrada en sí misma del pueblo alemán y en el movimiento nacionalsocialista sostenedor del Estado y del pueblo. Ya no hay ninguna garantía constitucional del territorio o de la existencia de las regiones actuales. A tales garantías no se puede llegar siquiera mediatamente, pongamos que a partir de la conservación de la institución del Consejo del Reich contenida en la ley constituyente provisional de 24 de marzo de 1933. Las regiones o provincias alemanas (Länder) de ahora, como las que eventualmente se formen, son realidades de un género propio y de un tipo totalmente independiente. No son ni Estados ni cuerpos municipales de administración autónoma. El concepto de autonomía municipal yo quisiera limitarlo con especial rigor, -dado que se trata de cuerpos territoriales- a la autonomía local (municipio rural y urbano, área de su mandato y del ámbito próximo), y la autonomía en lo demás referirla a organizaciones de categorías de profesiones ${ }^{26}$ o similares, cuyo lugar en la construcción general del Estado nacionalsocialista ha de determinarse más en detalle en la categoría "pueblo".

4. Una serie de cuestiones totalmente nueva se refiere a las relaciones legales entre Estado y movimiento. No obstante las muchas semejanzas del Estado nacionalsocialista con el Estado italiano fascista se muestran aquí grandes diferencias en la relación entre partido y funcionarios, partido y ejército, partido y Jefe (Führer) del Estado. El partido fascista es después de la ley de 14 de diciembre de 1929 claramente un "órgano del Estado" pero no de forma inmediata un órgano "estatal"; eso sólo lo es un determinado órgano del partido: el Gran Consejo del Fascismo ${ }^{27}$. El Partido Nacionalsocialista Alemán de los Trabajadores como portador de la idea estatal está ligado de forma indisoluble al Estado. Pero ni la organización del partido en su conjunto, ni una determinada jerarquía del partido tienen hoy (1 de diciembre de 1933) el carácter inmediato de un "órgano estatal". Que el partido nacionalsocialista no sea desde ningún punto de vista un "partido" en el sentido del sistema pluralista de partidos hoy superado, es algo que se entiende por sí mismo. Es el cuerpo directivo que sostiene al Estado y al pueblo, garantiza esta posición única y exclusiva de prioridad frente a todos los intentos de hacer resucitar el

\footnotetext{
${ }^{25}$ Nota del Traductor: en el original alemán aquí se utiliza el término "Stämmen", que cabría traducir por "pueblos", en el sentido de "tribus" o "linajes" pero el traductor italiano utiliza como correspondiente, tanto para este término como para "Arten", "stirpe".

${ }^{26}$ Nota del Traductor: tal vez Colegios Profesionales.

27 cfr. SANTI ROMANO, Corso di diritto costituzionale, 4 ed. 1933, p. 127 [En cambio G. AMBROSINI, II Partito fascista e lo Stato, Roma, 1934. Nota del Traductor al italiano]
} 
pasado pluralismo confesional, de clase y de otro tipo. Según la ley para la garantía de la unidad entre partido y Estado de 1 de diciembre de 1933 (RGBI. I, p. 1016) el partido es una corporación de Derecho público, y naturalmente en un nivel diferente y superior al de cualquiera de las muchas corporaciones de Derecho público que están bajo la supervisión estatal. El representante del Jefe (Führer) y el Jefe del estado mayor de la SA (milicia de asalto) se convierten en miembros del gobierno del Reich, para garantizar la colaboración más estrecha de los puestos de servicio del partido y de la SA con las autoridades públicas. Los miembros del partido y de la SA están sometidos en razón de sus especiales y mayores deberes a una jurisdicción especial del partido y de la SA. La conexión con el Estado se basa principalmente en uniones personales que conectan entre ellos a los Jefes de las diversas series organizativas, y no de una forma en absoluto casual, sino sobre la base real de la compenetración total de la unidad política. Estas uniones personales tienen ya en parte un carácter institucional: el Jefe (Führer) del movimiento Nacionalsocialista es Canciller del Reich alemán, sus paladines y subjefes están en otras posiciones políticamente directivas como ministros del Reich, Presidente de los ministros de Prusia, lugartenientes territoriales del Reich, como ministros prusianos, bávaros $\mathrm{u}$ otros, y así en adelante. Además de estas uniones personales pueden ser medios típicos de contacto entre Estado y partido ciertas posibilidades de influencia en especial las de carácter personal (derechos de propuesta, de nombramiento, de presentación de los puestos regionales o locales del partido). Toda otra conexión o separación también la compatibilidad por principio de los cargos en el partido con cargos estatales y de la administración autónoma y viceversa la incompatibilidad por principio- es una cuestión de oportunidad. Mas las líneas organizativas fundamentales vienen dadas por el triple acuerdo Estado, movimiento, pueblo, y han de entenderse lógicamente en este sentido, Estado, movimiento, pueblo, son diferentes pero no están divididos, ligados pero no fundidos.

La conexión entre Estado y partido no se puede entender con los conceptos hasta ahora usuales de Estado y no-Estado, partido y nopartido. Todas las incursiones de los tribunales, construidas con base en tales alternativas, en los asuntos de Estado y partido (correspondientes al ideal liberal de una constatación de la verdad que se lleva a cabo en continuas controversias legales) entran en contradicción con la construcción estatal en tres partes. Será necesario establecer la delimitación más neta de las diversas esferas con instituciones ya probadas como la denominada elevación de un conflicto ${ }^{28}$, y preservar a los tribunales, por el bien de su independencia, de los peligros de la esfera política. Dado que está claro que los enemigos declarados y ocultos del nuevo Estado se aprovechan de la vieja forma política de presentar una cuestión como una "pura cuestión de Derecho" para llevar al Estado o al movimiento ante un tribunal, y de esta forma -mediante la equiparación de las partes inserta en la lógica de un procedimiento procesal - dárselas de estar en igualdad de derechos con el Estado y con el movimiento. Un derecho de oposición como el que los tribunales

${ }^{28}$ (Konfliktserhebung). 
se han adjudicado frente a leyes del Reich (sentencia del tribunal del Reich; V Senado civil de 4 de noviembre de 1925, RGZ. vol. III, p. 320 s.) no cabe frente a las leyes gubernativas del gobierno del Reich. Antes que nada porque esta competencia legislativa del gobierno del Reich tiene carácter constitucional; en segundo lugar estas leyes gubernativas son contemporáneamente actos de un gobierno que mediante la capacidad legislativa ha restablecido el auténtico concepto de "gobierno"; y en tercer lugar tal intrusión de los tribunales sólo se puede justificar con la concepción bipartita (a tratar con más detalle en el cap. III) de Estado y no-Estado, resultando totalmente inconcebible con la nueva estructura general en tres partes de la unidad política.

Sería por tanto engañoso y peligroso utilizar aquí todavía las viejas distinciones entre Derecho y política, y plantear cuestiones alternativas como estatal y no-estatal, público y privado, jurídico y político. Estamos ante un problema de Derecho estatal completamente nuevo. El Partido nacionalsocialista no es un Estado en el sentido del viejo Estado, ni es no-estatal y privado en el sentido de la vieja contraposición entre la esfera estatal y la esfera aestatal ${ }^{29}$. Por tanto ni siquiera los criterios sobre responsabilidad, en particular la responsabilidad de cuerpo por abuso de oficio ${ }^{30}$ (art. 131 de la Constitución de Weimar, par. 839, BGBI.), pueden llevarse al partido o a las SA. En igual medida poco es lo que pueden inmiscuirse los tribunales con cualquier pretexto en cuestiones y decisiones internas de la organización del partido y romper desde fuera su principio del mando. La organización y la disciplina interna del partido que sostiene al Estado y al pueblo son asunto suyo: él tiene que desarrollar sus propias reglas con el más estricto sentido de la responsabilidad frente a sí mismo. Los cargos del partido a los que les incumbe esta tarea han de desempeñar una función de la que depende nada menos que el destino del partido y con él también el destino de la unidad política del pueblo alemán. Esta gigantesca tarea, en la que se acumula todo el riesgo de la política, ninguna otra autoridad, y menos que ninguna un tribunal civil actuando con formas judiciales, puede sustraérsela al partido o a las SA. Aquí el partido se basa internamente en sí mismo ${ }^{31}$.

\section{LA CONSTITUCIÓN BIPARTITA DEL ESTADO DE LA LIBERALDEMOCRACIA Y EL ESTADO DE FUNCIONARIOS ALEMÁN}

1. La nueva construcción estatal del siglo $X X$ en tres partes ha superado desde hace mucho tiempo el esquema estatal y constitucional en dos partes de la liberaldemocracia del siglo XIX. El Estado constitucional burgués del XIX está dominado por esta bipartición hasta en los detalles de su organización legislativa, administrativa y judicial, es más hasta en las últimas ramificaciones de teorías e ideas aparentemente totalmente abstractas. Esto aparece "ideológicamente" (una palabra típica y específica del liberal siglo

\footnotetext{
29 Nota del Traductor: "libre del Estado" en el original alemán.

${ }^{30}$ Nota del Traductor: entendemos que se refiere a "abuso de poder" o "abuso de autoridad".

31 Nota del Traductor: en el original alemán "ganz auf sich stehen" que vendría a ser "... es totalmente autónomo", o "autosuficiente".
} 
$\mathrm{XIX)}$ en las conocidas y bien amadas contraposiciones, intercambiables y negociables, ahora "oscilantes" ahora alternativas, de Derecho y fuerza, Derecho y Estado, Derecho y política, espíritu y potencia, espíritu y Estado, individuo y colectividad, Estado y sociedad, etc. etc. Además la bipartición tiene además un significado constructivo y organizativo muy concreto. Se ha creado, retomando una expresión concebida por el Comisario del Reich para la justicia, Doctor Frank ${ }^{32}$, una "configuración de cosas" propia, conforme con su espíritu. Los ulteriores efectos tanto de la "ideología" liberal como de la construcción estatal en dos partes dominan tanto en el pensamiento jurídico como en la forma de hablar de los juristas educados en el sistema liberal hasta el día de hoy. El liberal llama "Estado constitucional"33 solamente al Estado construido en dos partes; un Estado construido de otra forma "no tiene una Constitución", no es un "Estado con Constitución" y naturalmente ni siquiera es un "Estado constitucional" 34 , no es "libre", sino que es una "autocracia", "dictadura", "despotismo", etc. El vocabulario de esta lucha política es aquí muy rico, pero en la realidad - o sea en la utilización política de un determinado concepto de "Derecho" y "Estado constitucional"- es siempre lo mismo. Por tanto es necesario adquirir consciencia no sólo de la oposición ideológica, sino también de la construcción estatal levantada sobre ella y de su adecuación institucional y conceptual. De otro modo el pensamiento liberal empuja al movimiento hacia el Estado, y luego al Estado, pasando por el "Estado constitucional", hacia un "Derecho" opuesto al Estado, es decir al sistema liberal del siglo XIX.

La construcción en dos partes se basa en la oposición entre Estado y persona libre individual, entre poder estatal y libertad individual, entre Estado y sociedad estatal, entre política y esfera privada, esta última apolítica, por tanto irresponsable e incontrolada. Con esta bipartición se explica el esquema constituyente típicamente bipolar del Estado constitucional burgués, cuya Constitución, como es sabido, consistía en una parte de derecho fundamental, o sea derechos fundamentales y derechos de libertades de la sociedad, compuesta por individuos libres y ella misma libre, es decir no estatal y sin "Constitución"; y una parte normativa organizativa, o sea vinculante y constituyente del Estado. La parte liberal de los derechos fundamentales no es una Constitución en el sentido organizativo; diseña por el contrario la esfera, no constituida y autoorganizada, de la libertad; en cambio la parte organizativa de la Constitución estatal es la Constitución del Estado, es decir vinculación, delimitación y limitación del poder político del Estado. La denominada "preeminencia de la ley" sobre todos los otros tipos de manifestaciones estatales se dirige a someter políticamente al Estado a la sociedad que se pretende apolítica; dado que la ley en este sistema de ordenamiento es esencialmente una resolución del parlamento, y el parlamento es la representación de la sociedad no estatal frente al Estado. El principio organizativo reconocido universalmente de la llamada diferenciación de los poderes, con su tripartición en legislativo, ejecutivo y judicial, tenía el mismo sentido político, el de dividir el poder estatal de forma que la aestatal sociedad pudiese dominar y "controlar" eficazmente al "ejecutivo" estatal, es decir a la realidad del mando estatal. Todo iba dirigido a regular y controlar al poder político del Estado, y a defender la esfera de libertad de la sociedad de

\footnotetext{
32 Jur. Woch., 1933, p. 2001.

${ }^{33}$ Nota del Traductor: en el original alemán Schmitt dice "Estado de Derecho".

${ }^{34}$ Ver nota 31.
} 
"intervenciones" ${ }^{35}$ del Estado. Una justicia independiente del Estado debía dotar a la defensa frente al Estado de seguridad con forma jurídica y procesal. La justicia tenía en este sistema constitucional, desde el punto de vista de la organización, una interesante posición intermedia entre el mecanismo estatal de mando y la esfera social aestatal, siendo por un lado una función estatal, y por otro lado independiente frente a las órdenes de servicio de superiores estatales; era por tanto un instrumento adecuado para influir políticamente en este Estado en nombre del "Derecho" y mantenerlo en un puño.

Los derechos fundamentales y de libertad del sistema estatal y constitucional liberaldemócrata son esencialmente, por su sentido, derechos de la persona privada individual. Únicamente por esta razón pueden valer como "apolíticos". Por tanto no son siquiera un principio constructivo estatal, no son una Constitución, sino sólo principios que dominan a la Constitución estatal, y que deben dar al Estado sentido y finalidad, su justificación y sus límites. La construcción estatal y constitucional liberal procede a una contraposición simple e inmediata entre Estado e individuo privado. Sólo partiendo de esta contraposición resulta natural levantar un edificio de medios e instituciones legales de protección, para defender al indefenso individuo, pobre y aislado, ante el potente Leviatán "Estado". Sólo por la seguridad del pobre individuo tienen sentido la mayor parte de las instituciones de protección legal del denominado Estado constitucional, y se puede comprender que la protección del Estado tome cada vez más forma judicial y que termine cada vez más en una decisión judicial independiente del Estado.

Pero todo esto se convierte en absurdo cuando fuertes asociaciones $u$ organizaciones colectivas ocupan la esfera no estatal y apolítica de la libertad, y estas "autoorganizaciones" aestatales (pero en absoluto apolíticas), por una parte acogen de una forma cada vez más fuerte y estable a las personas individuales, y por otra con diversos títulos jurídicos (como pueblo, como sociedad, como burguesía libre, como proletariado productivo, como opinión pública, etc.) vienen a posicionarse contra el Estado. Tras el parapeto de la seguridad de la libertad individual de personas apolíticas y necesitadas de defensa se ocultan luego fuerzas políticas del más diverso tipo. Asociaciones no estatales, pero como se ha dicho bien políticas, dominan entonces tanto la voluntad estatal (por la vía de la legislación) cuanto también (mediante una coacción social y "puramente de Derecho privado") al individuo, al que aquéllas mediatizan. Éstas se convierten en portadoras auténticas y reales de las decisiones políticas, y manejan los instrumentos del poder del Estado; pero dominan desde la esfera individual, libre de Estado y Constitución, y no "pública", y escapan así a toda responsabilidad y peligro político. En la Constitución estatal del Estado constitucional liberaldemócrata es prácticamente imposible que éstas aparezcan jurídicamente como lo que son en la realidad política y social, porque el esquema liberal en dos partes no tiene un sitio para ellas. Todo intento de incluirlas en él hace saltar el Estado liberaldemócrata y su sistema. Por tanto si consiguen tales ligas ${ }^{36}$, por la vía de los partidos políticos dominados por ellas, apoderarse de las posiciones y de los medios del poder

\footnotetext{
35 Nota del Traductor: tiene el sentido de "agresiones".

${ }^{36}$ Nota del traductor: el traductor italiano traduce un mismo término alemán indistintamente como "asociaciones" y como "ligas", probablemente porque este término tiene unas especiales connotaciones historicistas en el pensamiento fascista.
} 
estatal -y esa es la evolución típica-, entonces ellas sirven en nombre de la autoridad estatal y de la ley a sus propios intereses y gozan de todas las ventajas del poder estatal sin renunciar a las ventajas de la esfera de la libertad, irresponsable y descontrolada porque se pretende apolítica.

Bajo el velo de la libertad liberaldemócrata y del Estado constitucional burgués pudo surgir de esta forma el sistema pluralista de un Estado de muchos partidos, como ha sido característico de los catorce años de la Constitución de Weimar. Una cantidad de partidos políticos de las más variadas especies, sindicatos y potentes ligas económicas, iglesias y sociedades religiosas, a menudo organizaciones cerradas de tipo nacional, confesional o de otro tipo, acuerdan bajo cuerda el ejercicio del poder estatal y el reparto de los ingresos nacionales. Como se pudo decir de la democracia ideal que ésta se basa en un "plebiscito cotidiano", así se puede decir de tal sistema pluralista que éste está integrado únicamente por el "compromiso cotidiano" de potencias y ligas heterogéneas y sólo en él existe, compromiso que como un nacionalsocialista ${ }^{37}$ dijo una vez de forma atinada es "siempre una vinculación de lo mejor con lo peor". El Derecho constitucional de un sistema como ese debe convertirse por su lógica interna en un arma puramente instrumental, técnica, un arma que cada uno maneja contra otros, también el extraño a la nación y el enemigo del Estado contra el connacional, así que todos los que están en el juego en tal sistema están obligados a un abuso obligatorio de todas las posibilidades legales. Grupos o ligas que permanecen en minoría, y que no consiguen entrar en una mayoría de coalición o en una de compromiso, deben forzosamente defender contra el Estado sus principios y fines, por más que aliberales o antiliberales, con argumentos y métodos liberaldemócratas. Todos los conceptos y las instituciones de tal sistema tienen que convertirse en falsos y absurdos. En el año 1932 yo he constatado que el poder de los gobiernos de la coalición de Weimar no se basaba en su legalidad, sino en el aprovechamiento político de las ventajas políticas de la posesión legal del poder. Todos los actores políticos, ligas de mayoría como ligas de minoría, gobierno como oposición, partidos nacionales e internacionales, fieles a la nación y adversarios de la nación ${ }^{38}$, se aprovechan sin reparos de todas las posibilidades legales y de todas las posiciones de poder que ocupan en tal sistema estatal y constitucional, porque la Constitución se había convertido en un medio simplemente funcional, neutral, y la perduración de la unidad política del pueblo en una simple escoria del "compromiso cotidiano". La estructura en dos partes del consiguiente "Estado constitucional" ${ }^{39}$ fundamentado en la contraposición de Estado e individuo, es y sigue siendo inadecuada y escasa ante la realidad de una vida política y social dominada por organizaciones no estatales o supraestatales políticamente potentes. Es capaz de distinguir solamente legalidad o ilegalidad, pero no correcto o erróneo ${ }^{40}$, ni amigo o enemigo.

Dos ejemplos de la incongruencia de toda Constitución liberaldemócrata

\footnotetext{
${ }^{37}$ KARL FIEHLER, Nationalsozialistische Gemeindepolitik, München, 1932, p. 12.

${ }^{38}$ Nota del Traductor: en el original alemán, en ambos casos, la referencia no es a la nación sino al pueblo.

39 Nota del Traductor: una vez más en el original alemán lo que aparece es "Estado de Derecho". No vamos a cansar al lector repitiéndolo en cada ocasión, quede constancia de que este cambio por el traductor italiano es muy recurrente en el texto.

40 Nota del Traductor: en el original alemán "acorde y contrario a Derecho"
} 
respecto de la realidad de la vida política y social actual pueden hacer más intuitiva esta situación.

a) La segunda parte principal ("derechos fundamentales") de la Constitución de Weimar, llena de contradicciones internas, tanto respecto de sí misma como respecto de la primera parte, la organizativa ${ }^{41}$. La Constitución de Weimar, conforme al esquema liberaldemócrata, está construida de forma bipartita. Pero la segunda parte, bajo el título "Derechos y deberes fundamentales de los alemanes" contiene sólo en muy pequeña parte derechos liberales de libertades de la persona individual. Además esta parte de la Constitución quisiera hacer justicia a la realidad de la vida social actual. En consecuencia otras numerosas disposiciones de esta "parte de los derechos fundamentales" garantizan y establecen cosas más bien contradictorias para una construcción constitucional liberaldemócrata, como instituciones y pretensiones de Derecho público de iglesias y sociedades religiosas (art. 137 s.), la institución de Derecho público de los funcionarios de carrera (art. 129), la institución, también de Derecho público, de la autonomía municipal (art. 127). También los sindicatos obreros y las ligas patronales son reconocidos en esta parte de la Constitución (art. 165), aunque éstos hayan preferido hasta ahora permanecer como sociedades de Derecho privado; e incluso no sujetas a Derecho. Que fuertes ligas colectivas como los sindicatos sean "reconocidas" en una Constitución estatal, y que con todo ellas quieran y puedan permanecer como asociaciones puramente de Derecho privado, es sintomático de la confusión de un Estado de tal tipo. Pero tampoco las otras instituciones de Derecho público de la denominada parte de los derechos fundamentales -iglesias, municipios y funcionarios de carrerapodían en modo alguno, en un sistema tal, renunciar a aprovecharse de la forma más amplia, por un lado, de los distintos partidos políticos, y por otro, contemporáneamente, de apoyos y organizaciones auxiliares de Derecho privado. A las iglesias se había incorporado y apoyado no sólo el correspondiente partido político, sino también un potente cuerpo social de Derecho privado, con numerosas asociaciones religiosas, culturales y de la sociedad ${ }^{42}$, en parte incorporadas, en parte reconocidas, en parte permitidas, en parte al menos toleradas. Municipios y asociaciones municipales, mediante personas jurídicas de Derecho civil y mercantil de todo tipo, sabían organizarse económicamente y eludir la vigilancia estatal. Junto a la institución de Derecho público de los funcionarios de carrera surgieron sindicatos de funcionarios, de Derecho privado. Este Estado pluralista consistía finalmente sólo en conexiones transversales y en vínculos y amalgamas de intereses y funciones privadas y públicas. En tal sistema se puede ser a la vez diputado del Reich, delegado del Consejo del Reich ${ }^{43}$, alto funcionario estatal, alto dignatario eclesiástico,

\footnotetext{
${ }^{41}$ Nota del Traductor: Frase reconstruida a partir del texto alemán porque en la traducción italiana se ha producido algún error que la hace prácticamente incomprensible.

${ }^{42}$ Nota del Traductor: En el original alemán se utiliza el término "gesellige Verbände", a traducir como "asociaciones de amigos", con lo que parece que Schmitt quiere hacer referencia a las del tipo de las asociaciones de veteranos de guerra, por ejemplo.

${ }^{43}$ Nota del Traductor: el término "delegado" por el que opta el traductor italiano, no reporta la idea de "Bevollmächtigter", pues al ser el Reichsrat otra cámara, tal vez debería
} 
jefe de partido, consejero en la administración de diversas sociedades y más cosas aún; es más, este curioso sistema de hecho sólo funciona mediante estas conexiones transversales. Así todo era compatible con todo, y Alemania era el "reino de las compatibilidades ilimitadas". Tras la bipartición del esquema constitucional liberaldemócrata crecía lujuriante un pluralismo anárquico de poderes sociales, en una mezcla caótica de lo estatal y lo no estatal, lo público y lo privado, lo político y lo falsamente apolítico.

b) Otro ejemplo evidente de la insuficiencia del esquema constitucional en dos partes lo ofrece la historia del plan Constitución económica, que en el artículo 165, al final de la parte de la Constitución de Weimar sobre los derechos fundamentales, venía incluso, por lo que se dice, "con una sólida base". En el sistema liberaldemócrata en dos partes una Constitución económica resulta imposible. O se ejecuta totalmente, y entonces arranca de sus cimientos todo el sistema en dos partes; o es una construcción accesoria prácticamente insignificante, con instituciones del tipo del consejo provisional del Reich para la economía introducido con el Decreto de 4 de mayo de 1920, que ha quedado sin significado práctico reseñable. No dependió siquiera tanto de la mala voluntad consciente de todos los partidos interesados en el sistema pluralista, cuanto de la correspondiente lógica interna del Estado liberaldemócrata de Weimar, que los múltiples intentos de introducir un consejo económico del Reich definitivo y real tuviesen que fallar miserablemente. Una Constitución social y económica precisamente sólo es posible en un Estado moderno, con una estructura en tres partes.

2. Hoy nosotros, no sólo conocemos las contradicciones internas de tal sistema pluralista que vive detrás de la legalidad del sistema constitucional liberaldemócrata; hoy nos sentimos más allá dado que nuestro conjunto estatal en tres partes, frente a la bipartición liberaldemócrata (de Estado y sociedad, o Estado y esfera política de libertad) es el presupuesto natural de la honestidad y de la limpieza política. La bipartición nos resulta ya un enmascaramiento y una ocultación de fuerzas y potencias no estatales, pero ciertamente tampoco apolíticas, más bien supraestatales, a menudo enemigas del Estado, que bajo la protección de las "libertades" liberales pueden hacer su papel de entidades ${ }^{44}$ políticamente decisivas en secreto, anónimamente, invisibles e irresponsables.

También en las formaciones e instituciones políticas de tiempos pasados nosotros seguimos reconociendo hoy, a través de todos las capas de libertad e igualdad, a las entidades y a las organizaciones realmente sostenedoras del Estado. Dado que el pasado recibe su luz desde el presente para todo espíritu cognoscente, es un espíritu contemporáneo. Así nosotros vemos hoy por ejemplo en diversas épocas y en algunos Estados que la iglesia con su clero o con una orden determinada asumió el papel de organización sostenedora del Estado; en otros casos pudo ejercer esta función una orden secreta como la masonería; en Estados marineros y mercantiles el ordenamiento general de la unidad política ha estado sostenido las más de

denominarse "diputado" o "comisionado".

${ }^{44}$ Nota del Traductor: en el original alemán se usa "Grö $\circledast e$ ", "magnitudes", aunque también resulta extraño en el contexto. 
las veces por la economía o por un determinado grupo profesional. Cabe imaginar numerosas conexiones transversales. Sin embargo en el Estado actual de nuestro conocimiento ${ }^{45}$ político, nosotros volveremos siempre a la estructura en tres partes y a la cuestión de la organización sostenedora del Estado. Por otra parte ya sólo entendemos como fachada el esquema constitucional liberaldemócrata de Estado e individuo, norma organizativa y derechos de libertades. Cada vez parecen más grandes y potentes entonces tanto la acción como la tarea del movimiento nacionalsocialista alemán, que manifiesta abiertamente su responsabilidad histórica y asume para sí de forma totalmente pública la misión gigantesca de una organización sostenedora del Estado y del pueblo.

Por lo que se refiere en concreto al desarrollo del pensamiento estatal alemán, resulta claro que las peculiaridades históricas tanto del funcionario alemán y del ejército, como de la organización del partido nacionalsocialista, como también de la esfera social y económica, son en Alemania especialmente grandes y no comparables entre ellas. Y luego la Teoría del Estado alemana, como se ha dicho, hasta mediados del siglo XIX, -por tanto hasta la victoria de la forma de pensar liberal y de un positivismo científico-, no ha conocido el esquema bipartito de la contraposición entre Estado y sociedad. Para Hegel, por ejemplo ${ }^{46}$ las "corporaciones" constituyen el paso de la sociedad burguesa al Estado; el Estado no es para él en modo alguno sólo aparato burocrático por un lado y sociedad libre burguesa por otro. También Lorenzo von Stein, en 1865, en su Teoría administrativa pone de relieve junto al poder gubernativo como conjunto de los cargos oficiales de la administración autónoma de las provincias, municipios y corporaciones; y a las asociaciones, por él asignadas a las esfera del Derecho público, como parte esencial de la vida pública. Es verdad que luego estos conocimientos estatales constructivos se perdieron en "teorías sindicales", y tras el 1800 ya sólo domina la sociedad o la falta de relaciones del denominado positivismo. Un profesor de Derecho del Estado extraño a la estirpe alemana pudo liquidar la obra de un Lorenzo von Stein como "ingeniosidad desconcertante". Pero tras la fachada del Estado constitucional liberal construida con dos articulaciones, y de la teoría positivista del Derecho público en el sentido adecuado, el Estado alemán ha permanecido, también durante el liberal siglo XIX, como un Estado militar y de funcionarios, y por tanto un Estado administrativo. En este hecho histórico está el sentido último y auténtico de la conocida frase de Otto Mayer: "El Derecho constitucional pasa, el Derecho administrativo permanece". Este Derecho expresa la superioridad del funcionario monárquico, portador del poder ejecutivo, sobre el sistema constitucional liberal, de forma más decisiva de lo que el mismo autor tal vez hubiese podido creer.

Sobre todo fue decisivo que el ejército y el funcionario alemán en la mayor parte de los Estados alemanes, -y especialmente en Prusia, el Estado alemán dirigente- cargasen durante un siglo también con la función de grupo sostenedor del Estado. Aparato de fuerza estatal y organización portadora del Estado coincidían. La clase de los funcionarios alemanes no ha sido nunca un simple "aparato" burocrático en el sentido de las democracias liberales occidentales. De esta clase dice O. Mayer con razón que es, "especialmente la clase culta de los funcionarios de carrera, que ocupa todos

\footnotetext{
45 Nota del Traductor: en el original alemán "conciencia”.

${ }^{46}$ Georg Wilhelm Friedrich Hegel, Grundlinien der Philosophie des Rechts, 1821, pag. 250 y ss. Nota del Traductor: en el original alemán la cita es de Rechtsphilosophie, parágrafo 250 y S.
} 
los cargos decisivos, no un instrumento, sino una fuerza independiente en el Estado". Ésta es la realidad histórica que en la filosofía del Estado de Hegel, en su teoría del Estado como reino de la razón objetiva, ha encontrado un sistema teórico y filosófico. Ciertamente la doctrina alemana del Derecho estatal, bajo el pretendido positivismo, renunció pronto, como se acaba de decir, a toda profundización y defensa científica de esta situación. Sólo en las teorías de historiadores y economistas alemanes de la generación anterior, por ejemplo en Adolfo Wagner o Gustavo Schmoller, se ha mantenido el gran concepto político alemán traicionado por los juristas, y permaneció viva, aunque relativizada como un concepto "historiográfico", la conciencia de que el Estado de la clase culta e incorruptible de los funcionarios alemanes está por encima de la sociedad burguesa". Así se hizo posible un Estado de funcionarios, con una política social y cultural. Pero esto no bastaba para sostener espiritualmente a un Estado que estaba amenazado desde dentro y desde fuera. Durante medio siglo nuestra clase alemana de los funcionarios educada casi sólo jurídicamente, estaba yerma espiritual y políticamente en un pretendido "positivismo". Se ha convertido así en incapaz de cumplir con los deberes decisivos de una clase políticamente dirigente.

Mientras que la realidad de este Estado alemán de militares y funcionarios existía, y el Estado podía en consecuencia ser concebido como una esfera de la "moralidad y la razón objetiva" que estaba por encima de la sociedad, era posible un Estado de funcionarios con una política social y cultural, que en todos los casos no era un simple instrumento en las manos de fuerzas "sociales" extrañas, francas u ocultas, visibles o invisibles. Además la realidad de un Estado tal de militares y funcionarios se daba de golpes continuamente con el sistema de normas entonces válido y con todos los principios de la Constitución liberaldemócrata, es más con todo el "constitucionalismo" del siglo XIX. El éxito político extraordinario que Bismarck logró entre 1866 y 1871 le podía llamar a engaño sobre el hecho de que desde 1848 el Estado de funcionarios alemán estaba a la defensiva, espiritualmente. Ni la mezcla de retórica y de sofística que Federico Julio Stahl -su verdadero nombre es Joll Jolson- proporcionó a los conservadores prusianos, ni el positivismo cínico de un Laband, eran doctrina estatal y jurídica alemana; no obstante todas las aparentes diferencias ellas no hacían en el fondo más que preparar el camino para fuerzas y potencias políticas de la liberaldemocracia, que se presentaban en nombre del "Estado constitucional", y del marxismo que presionaba inmediatamente tras ella.

Ciertamente ni siquiera la Constitución liberaldemócrata de Weimar y catorce años de dominio de un sistema pluralista de partidos pudieron destruir completamente la gran tradición del Estado de funcionarios alemán. Ya se había demostrado antes de la guerra mundial que la clase de los funcionarios alemanes, dividida en más de veinte Estados individualizados, por sí misma no estaba ya en situación de cumplir con ambas funciones, es decir la de aparato de autoridad estatal, objetivo y neutral, y la de grupo políticamente dirigente, sostenedor del Estado. Era normal que el funcionariado buscase cada vez más su verdadero valor en la seguridad y valoración positiva y profesional de un funcionamiento administrativo y judicial ejemplar, en vez de en la responsabilidad de resoluciones políticas. Por objetividad, neutralidad y positivismo no estaba ya en situación de reconocer por sí, con clara resolución política, al enemigo del Estado, y mucho menos de vencerlo. Se perdió en una positivista fidelidad absoluta a la ley, que al final era ya sólo la legalidad de un Estado de legislación parlamentaria, y cuya base, la ley, ya 
tenía poco que ver con el "Derecho" en un sentido positivo y sustancial, dado que esta ley era ya sólo el resultado de compromisos de una coalición heterogénea. Así ninguna defensa seria podía ya obstaculizar la aspiración a la dirección de los partidos parlamentarios. Durante la guerra mundial un grupo de políticos de los partidos parlamentarios pudo penetrar en el Estado alemán sin aportar ningún servicio político, llevado únicamente por la necesidad de que el vacío en la dirección política debía ser rellenado de algún modo. Tras el derrumbamiento del Estado monárquico de funcionarios, en el Estado pluralista de los partidos de la Constitución de Weimar, de 1919 a 1932, la clase de los funcionarios alemanes encontró su justificación ya sólo en una función de acomodo mediador y en una especie de posición de árbitro neutral entre intereses de partido organizados. No estaba ya por encima de la sociedad, sino entre los estratos de la sociedad. Pero de esta forma cayó en el juego del sistema pluralista; a la larga, para mantenerse, tuvo que convertirse en compañera de juegos y en cómplice político del comercio de compromisos, desistiendo así de su esencia acrecentando el sistema político con una ulterior unidad. El "equilibrio neutro" mejor intencionado, aunque ciertamente fuese moralmente superior a un sistema de partidos enteramente corrupto, podía ser sólo un mal e insuficiente sustituto de la ausente dirección política. Ni la clase neutral de los funcionarios, ni el sistema pluralista de los partidos con su funcionamiento parlamentario, han cumplido con su tarea estatal ni han producido desde su interior una dirección política. Por eso han fracasado.

Sólo las experiencias de 1932 han hecho fecunda esta consciencia también para la gran mayoría del pueblo alemán. El "golpe prusiano" del 20 de julio de 1932 ha alejado de Prusia al gobierno del sistema Weimar y le ha arrancado de las manos el estado prusiano, potente conjunto de fuerza y potente mecanismo de mando. Pero ninguno de los dos pretendidos gobiernos "autoritarios" de von Papen (de junio de 1932 a noviembre de 1932) y de Schleicher (de noviembre de 1932 a enero de 1933), apoyados sólo en la Reichswehr ${ }^{47}$ y en el aparato del poder estatal prusiano, pudieron rellenar el vacío político, es decir la falta de dirección política. Pablo Ritterbuch en su escrito aparecido en noviembre de 1932 "El compromiso constitucional de Weimar, el experimento del gobierno presidencial y la idea estatal nacionalsocialista" ha mostrado desde el punto de vista de la doctrina del Derecho del Estado la desesperación implícita en este estadio de desarrollo del pluralismo. La decisión del Tribunal de Justicia del Estado de 25 de octubre de 1932 no ha restaurado si hemos de decir la verdad el sistema de Weimar, pero no podía darle al gobierno del Reich lo que le faltaba y que él no podía osar coger; esta sentencia rechazó también reconocer al enemigo del Estado como enemigo del Estado, y ayudar a ponerlo en una situación desde la que le fuese imposible hacer daño. Solamente cuando el Presidente del Reich, el 30 de enero de 1933, nombró Canciller del Reich al Jefe (Führer) del movimiento nacionalsocialista, Adolf Hitler, el Reich alemán tuvo de nuevo una dirección política y el Estado alemán encontró la fuerza para aniquilar al marxismo enemigo del Estado.

Este 30 de enero el Estado de funcionarios hegeliano del siglo XIX, en el que era característica la unidad de clase entre los funcionarios y el grupo sostenedor del Estado, ha sido sustituido por otra construcción estatal. En el día de hoy por tanto, se puede decir, "Hegel ha muerto". Pero esto no

${ }^{47}$ Nota del Traductor: Ejército del Reich. 
significa que la gran obra del filósofo del Estado alemán se haya quedado sin significado, y que se haya desechado la idea de una dirección política que esté por encima del egoísmo de los intereses sociales. Lo que en la potente construcción espiritual de Hegel es, por encima del tiempo, grande y alemán, sigue aún activo también en la nueva forma ${ }^{48}$. Sólo las formas del Estado hegeliano de funcionarios, formas correspondientes a la situación interna del Estado del siglo XIX, son apartadas, y sustituidas por otras formaciones correspondientes a nuestra realidad actual.

Hoy el Reich alemán, la unidad política del pueblo alemán, sólo se puede comprender ya con la ayuda del triple acuerdo de Estado, movimiento, pueblo. La inmanente tarea política del partido nacionalsocialista sólo así resulta reconocible. El funcionario de carrera alemán es liberado de una posición híbrida convertida en poco clara e insostenible, y ha sido salvado del peligro de ser rebajado, a la manera liberaldemócrata, al papel de instrumento ciego de potencias no estatales, sociales, es decir políticamente irresponsables, invisibles. Sin embargo por otra parte la tarea del movimiento no se agota con esto, en llevar nueva sangre al cuerpo agarrotado de un Estado de funcionarios, y luego, una vez diluido en el "Estado", retirarse. Diferentes, pero no divididas, unidas, pero no fusionadas, las tres grandes "ruedas motrices", como las denominó una vez el Presidente de los ministros de Prusia, Göring, deben discurrir una junto a otra, cada una según su ley interna y todas al unísono con la totalidad política que es llevada por el movimiento.

\section{IV. \\ MANDO E IGUALDAD DE ESTIRPE COMO CONCEPTOS FUNDAMENTALES DEL DERECHO NACIONALSOCIALISTA}

1. El nacionalsocialismo no piensa de forma abstracta y mecánica. Es enemigo de todo artificio normativista y funcionalista. Él asegura y cultiva toda auténtica sustancia nacional allí donde la encuentra, en el país, en la estirpe o en la clase. Ha creado para los campesinos el Erbhofrecht ${ }^{49}$; ha salvado a la clase del campesino; purificado la clase de los funcionarios alemanes de elementos de estirpes extrañas, le ha devuelto así su carácter de grupo. Tiene el valor de tratar con medidas distintas a las cosas distintas, y de imponer diferenciaciones necesarias. Por ello reconocerá, donde esto tenga sentido, una jurisdicción de clase, como, con la ley de 12 de mayo de 1933 (RGBI. I, p. 264), se ha introducido de nuevo para el ejército, sobre la base de la vieja regulación del tribunal penal militar. También para ciertas organizaciones del partido, como las

\footnotetext{
${ }^{48}$ Nota del Traductor: Schmitt usa el término "Gestalt", de difícil traducción. Vendría a ser la nueva "configuración" o "ideación". Este término podría venir de las influencias orientales tan en boga en los años 30. Para los nazis la intuición o el acceso al espíritu entendido como "mente" se llevaba a cabo como en ciertas filosofías de la India con el hacha de dos hojas que casualmente forma parte de la tradición germana nórdica- con una de las cuales se corta lo exterior pero que a la vez con la otra le abre a uno la mente y permite que entre la inspiración. Hay de hecho una filosofía de la Gestalt que no es en absoluto nazi y que ha inspirado a todos los movimientos alternativos de concepción del mundo y de la Tierra como un todo interrelacionado, el "holismo".

${ }^{49}$ Nota del Traductor: vendría a significar "derecho inalienable a la tierra".
} 
SA o las SS, cabría pensar en una especie de disciplina de clase con jurisdicción de clase. Con la formación de auténticas clases, el campo de la jurisdicción de clase se ampliará por sí mismo. De otra forma, pero con el mismo sentido con la autonomía específica y concreta, el nacionalsocialismo puede hacer justicia en el campo de la autonomía municipal a las diferencias entre pueblo, ciudad de campo, municipio industrial, gran ciudad y metrópolis, sin verse entorpecido por las falsas ideas igualitarias de un esquema liberaldemócrata.

a) Pero el reconocimiento de la multiplicidad de la vida particular y específica llevaría enseguida de nuevo a una infeliz degeneración pluralista del pueblo alemán en confesiones, estirpes, clases, grupos y grupos de interés, si un Estado fuerte no elevase, garantizándola por encima de toda pluriformidad, la totalidad de la unidad política. Toda unidad política necesita de una coherencia y de una lógica interna de sus instituciones y de sus sistemas de normas. Precisa de un pensamiento formal unitario, que configure totalmente todas las esferas de la vida pública. También en este sentido no hay Estado normal que no sea total. Cuanto más múltiples son los puntos de vista para las reglas y las instituciones de las diversas esferas de la vida, de forma igualmente decidida debe reconocerse y mantenerse firme por otra parte un principio fundamental unitario y consecuente. Toda incertidumbre y toda escisión se convierte en un punto para la inserción de formaciones antes neutrales frente al Estado, luego enemigas del Estado y centro de brechas y laceraciones pluralistas. Un Estado fuerte es el presupuesto para una vida fuerte propia de los diversos miembros del mismo Estado. La fuerza del Estado nacionalsocialista está en esto, que está dominado y convencido por la idea del mando de arriba abajo y en cada átomo de su existencia. Este principio, mediante el cual el movimiento se ha hecho grande, debe ser aplicado hasta el fondo, como requiere su sentido, tanto en la administración estatal como en las diversas esferas de administración autónomas, teniendo en cuenta naturalmente las modificaciones impuestas por la particularidad de cada materia. No sería admisible querer excluir de la idea del mando a una esfera importante cualquiera de la vida pública.

El Estado militar y de funcionarios del Ochocientos alemán, exteriormente tan fuerte, ha cometido el grave error político de dejar surgir en la administración autónoma municipal un principio informante diferente del "poder ejecutivo" estatal, (según el sentido que entonces tenían las palabras) del Estado mismo. Que la representación municipal derivase de elecciones, por sí mismo no debería necesariamente haber dado pie a una escisión dentro del Estado, dada la diversidad esencial entre municipio y Estado; pero la representación municipal elegida se entendió como el verdadero sostén y representante del municipio precisamente porque era electa, y con ello se reconocía para el municipio un principio formal que contradecía al Estado monárquico. La autonomía municipal se convirtió así en un punto de invasión parlamentaria liberaldemócrata en un Estado de funcionarios monárquico-autoritario. El barón von Stein entendió ya en 1810 que él no había "prestado suficiente atención a la diferencia entre Constitución y administración autónoma". Bajo el típico pretexto de que se trataba de asuntos "apolíticos" de administración 
autónoma, la burguesía liberal se creó una esfera hurtada al Estado, de Derecho público o "libre del Estado", en la que valían otros ideales políticos y otros principios formales e informantes distintos de los del Estado. Bajo mantos de Derecho alemán como "idea cooperativa", "libertad de administración", "asuntos propios", y de ahí en adelante, una doctrina jurídica que sabía a donde apuntaba removió el principio de mando (Führerprinzip) de la construcción estatal prusiana. La teoría de la igualdad esencial de todas las asociaciones humanas, en concreto también de municipio y Estado, apoyó de forma muy eficaz la conquista del Estado prusiano por parte de un principio informante radicalmente extraño a él.

Es verdad que el Estado militar y de funcionarios alemán mostró una tenaz fuerza de resistencia frente al avance aparentemente irresistible de las ideas liberales; él creó una compenetración organizativa ejemplar entre administración estatal y administración autónoma municipal, de la cual el Landrat (Presidente del distrito) ${ }^{50}$ prusiano es el ejemplo más célebre. También la regulación electoral en tres clases que estaba en vigor para las elecciones municipales impidió las últimas consecuencias de una liberaldemocracia corriente. Pero no hay que ignorar que el Estado no estaba a la altura del adversario que avanzaba ora como nacional-liberal, ora como liberal-conservador, ora como partidario del principio cooperativo, ora como comunal-liberal; y que también aquí, como se ha mostrado antes (III, 2), combatió estando a la defensiva. En consecuencia finalmente fue vencido. No hace falta demostrar con profundidad que en nuestro Derecho estatal y administrativo actual las cosas deben ser de otra manera. En un Estado total no pueden darse manifestaciones políticas de protesta de un parlamento local como por ejemplo aquella resolución del consejo municipal de Berlín del año 1808, -que se pretendía de hecho "apolítica", un "puro asunto de administración", un "simple acto de piedad",- para colocar una corona sobre las tumbas de los revolucionarios de marzo de 1848 (Sentencia del OVG. De 9 de julio de 1898), o aquel conflicto de banderas en Potsdam entre Estado y municipio, ${ }^{51}$ que con la sentencia del Tribunal de justicia del Reich alemán de 9 de julio de $1928^{52}$ se decidió a favor del municipio.

b) La aplicación organizativa de la idea del mando nos solicita antes que nada, negativamente, que caigan todos los métodos esenciales y acordes con la forma de pensar liberaldemócrata. Cesa la elección desde abajo, con todos los residuos de las habituales maniobras electorales (las nuevas elecciones para la Dieta del Reich del 12 de noviembre de 1933 pueden entenderse, como se ha mostrado antes, sólo como parte constitutiva de una consulta popular). También los viejos procedimientos

\footnotetext{
${ }^{50}$ Nota del Traductor: Schmitt no dice "presidente", y Landrat es Consejo del Land.

51 También en la monarquía ausbúrgica las fuerzas disolventes del Estado, especialmente las nacionalidades en lucha contra la totalidad estatal, se han aprovechado de la autonomía municipal como puerta de entrada. Sucedió que el burgomaestre de una capital de distrito prohibió a los militares marchar por ciertas calles de la ciudad. Cfr. Verw. Archiv., XIX (1911), p. 448, un capítulo que contiene conjuntamente una bonita muestra del sentido y de la esencia del "Estado constitucional".

52 Hans-Heinrich Lammers, (a cargo de) Walter Simons, Die Rechtsprechung des Staatsgerichtshofs für das Deutsche Reich und des Reichsgerichts auf grund Artikel 13 Absatz 2 der Reichsverfassung, vol I, 1920-1928, Berlín, Stilke, 1929, pag. 276.
} 
de votación, con cuya ayuda la mayoría reunida de cualquier manera hacía convertirse en mayoría a una minoría y hacía de la votación un medio de poder para vencer y situar en minoría a los otros, no se pueden seguir repitiendo ya en un Estado de un solo partido. Finalmente las divisiones y los dualismos típicamente liberales de legislativo y ejecutivo, y en la organización municipal de órganos resolutorios y órganos administrativos y ejecutorios, han perdido su sentido. La competencia legislativa del gobierno del Reich es un primer ejemplo, que abre un nuevo camino, hacia esta anulación de artificiosas degeneraciones. Por todas partes es necesario que el sistema de repartición y de descarga de la responsabilidad sea sustituido por la clara asunción de responsabilidad por el Jefe (Führer) que reconoce abiertamente su orden, y que la elección sea sustituida por la selección.

Pertenece a la nueva idea del Jefe (Führer), que para el Estado nacionalsocialista es de una importancia específica y determinante, como un complemento natural la institución de un consejo del Jefe (Führer). Éste está al lado del Jefe (Führer) con sus consejos, sugerencias y pareceres; le apoya y le ayuda, le mantiene en un contacto vivo con el séquito y con la nación, pero no puede quitarle al Jefe (Führer) ninguna responsabilidad. No es una organización de desconfianza, de control y de descarga de la responsabilidad, ni debe representar ni expresar un dualismo interno (representación popular contra gobierno, representación municipal contra dirección municipal), y mucho menos un pluralismo. Por ello no puede permitirse que el consejo del Jefe (Führer) sea elegido desde fuera o desde abajo, sino que debe ser seleccionado por el Jefe (Führer), según ciertos principios de selección que tienen en cuenta sobre todo la conexión con la organización del partido que sostiene al Estado y al pueblo. De esta forma se hace también posible tener en cuenta ampliamente las particulares condiciones y necesidades locales y regionales, como también las objetivas y de las diferentes clases. Jefe (Führer) y consejo del Jefe (Führer) son un tipo de formaciones tan simples como elásticas en su aplicación concreta a los más diversos campos de la vida. Han encontrado su primera forma, intuitiva y ejemplar, en el consejo de Estado prusiano, la gran obra construida por el Presidente de los ministros de Prusia, Göring. En la ley prusiana del consejo provincial de 17 de junio de 1933 (GS., p. 254) la idea ya ha sido llevada desde la esfera del gobierno a la de la administración. Hoy debería profundizarse y reconocerse universalmente como principio.

2. Ante el significado fundamental del concepto de Jefe (Führer) se hace más necesario distinguir también teóricamente de forma clara, y garantizar su carácter especial del concepto esencial del Derecho nacionalsocialista, el concepto de dirección (Fürung). Para reconocer el concepto con su pleno significado y alejar el peligro de falsificaciones y opacidades es necesaria antes que nada una clara comparación con ciertos otros conceptos aparentemente afines. Dado que tales conceptos, que son de hecho necesarios y en su esfera indispensables, pero que están ya impregnados de otro espíritu, son utilizados con gusto para asimilar a ellos la idea de Jefe (Führer), y así, paralizar su auténtica fuerza. Resulta conocido que es una peculiaridad de la liberaldemocracia consecuente el ver como un ideal la "falta de Jefes" políticos. Pero no ha llegado todavía a la consciencia científica de la mayor parte de los 
juristas alemanes que desde hace un siglo hay todo un sistema de formación específica de conceptos que trabaja en esta eliminación de la idea de Jefe (Führer) y que las miras de tales conceptos son apuntadas sobre todo hacia allí donde deben necesariamente actuar de forma políticamente destructiva y de hecho aniquiladora.

El pensamiento jurídico estatal dominado por el principio fundamental de la seguridad, predictibilidad y mensurabilidad transforma todas las representaciones, conceptos e instituciones, bajo el pretexto de elaborar conceptos jurídicos, en abstracciones normativistamente predeterminadas. Se dice por ejemplo que todo deber, si ha de ser un deber legal y jurídicamente relevante, tiene siempre un contenido controlable normativamente y consiguientemente susceptible de la verificación por el juez. De esta simple forma se expulsa de la vida legal a otro tipo de deberes, inaccesibles para el pensamiento jurídico individualista-liberal, y se proporciona el monopolio de la cientificidad jurídica a una ideología política totalmente determinada (que no es en modo alguno de una especie particularmente jurídica o particularmente científica). Los deberes de fidelidad, por ejemplo, del séquito, de los funcionarios, de los connacionales, necesarios vitalmente para el Derecho de un Estado fundado por el Jefe (Führer) [Führerstaat] y que son totalmente, en el pleno sentido de la palabra, deberes legales, son reducidos con esta interpretación a asuntos "simplemente morales" o "simplemente políticos", y privados de su núcleo jurídico. En el proceso de Leipzig iniciado por el gobierno prusiano del sistema de Weimar, exonerado de la acusación, contra el Reich alemán, este orden de ideas ha celebrado sus triunfos. El deber de fidelidad de los Länder frente al Reich, que naturalmente es un deber legal ${ }^{53}$ de contenido político, con la ayuda de semejante separación liberal de Derecho y política fue destruido en su esencia, y por un representante especialmente típico del sistema de Weimar fue tildado irónicamente como algo "sentimental". Para esta concepción era "Derecho", como algo diferente de la "política", situar políticamente en un mismo plano a los nacionalsocialistas y a los comunistas; diferenciar a la organización comunista, o sea a un enemigo mortal peligroso del Estado alemán, de un movimiento nacional alemán, se consideraba por el contrario una falta contra la "igualdad ante la ley", o una valoración "política", en contraposición a una "legal" o "jurídica". Aquí se hacía evidente el núcleo antiestatal de la antítesis liberal entre Derecho y política. Ciertamente el Tribunal de Justicia del Reich alemán intentó en su sentencia de 25 de octubre de 1932 permanecer también a este respecto escrupulosamente "legal y neutral", y apartarse de la decisión. Así se explica el segundo paso, significativo palabra por palabra y frase por frase de las razones decisivas de esta célebre sentencia:

"Puede concederse que en tiempos de altísima tensión política en ataques públicos especialmente violentos de ministros de un Land a la política del Reich pueda encontrarse en algunos casos una transgresión del deber de fidelidad. La posibilidad de encontrar en tales ataques una falta al deber por parte del Land no puede sin duda excluirse ni siquiera por el hecho de que el ministro no actúe con carácter oficial, sino como particular o como miembro de un partido. Pero del análisis de las declaraciones del ministro Severing, también vistas a la luz de la

${ }^{53}$ Nota del Traductor: en realidad Schmitt habla de deber jurídico. 
situación general de entonces, resulta que éstas no traspasan los límites de la debida reserva, de forma que pueda verse en ellas una falta al deber del Land frente al Reich".

Otro ejemplo es el concepto de superintendencia, desarrollado en medio siglo de praxis liberal como concepto antitético del concepto de dirección política. Se entiende por sí misma que "superintendencia" en los diversos usos de la palabra (superintendencia del servicio frente a los funcionarios, superintendencia escolar, superintendencia municipal, superintendencia eclesiástica, etc.) la hay todavía hoy, y su esfera de validez permanece. En todo tipo de dirección se puede encontrar también algún modo de "superintendencia". Pero es necesario distinguir claramente las especiales esferas de validez de la superintendencia, y oponerse a la confusión que amenaza al concepto de la verdadera dirección desde el concepto de superintendencia.

La Constitución federal de Bismarck de 18 de abril de 1871 era la Constitución de una federación hegemónica; Prusia tenía la hegemonía, es decir la dirección política. Esto era indiscutido e indiscutible. Pero no estaba expresamente escrito en el texto de la Constitución, y como el concepto de dirección política se aparta de la forma de pensar del positivismo liberal, justo este concepto decisivo del Derecho del Estado federal alemán encontró poco interés en la teoría del Derecho del Estado. Uno se habría expuesto al reproche de ser "político" y "no científico", si hubiese hecho justicia a la verdad y a la realidad de esta formación de Estado federal construido todo él y enteramente sobre una base hegemónica. Así no se captó el concepto central de esta Constitución del Reich, y el concepto de superintendencia del Reich obtuvo una atención y un desarrollo tan amplios. Constituye un resultado lógico de este tipo de pensamiento jurídico estatal que el último trabajo sistemático sobre el Derecho federal de la Constitución de Bismarck, la obra de H. TRIEPEL, Die Reichsaujsicht ${ }^{54}$, considerase todo este Derecho sub specie de la superintendencia del Reich. Que un científico alemán como H. Triepel, que frente a los desvíos normativistas del Derecho estatal ha demostrado a menudo su sentido de la realidad política, llegase a este cambio de acento, muestra la sugestiva fuerza de las costumbres del pensamiento liberal-constitucionales, y la lógica interna de tales formas de pensar que pasan de la dirección a la superintendencia, y para las que incluso la Reichexekution era ya sólo un caso de la "superintendencia del Reich".

Con la Constitución de Weimar esta tendencia al concepto de superintendencia habría todavía de desarrollarse y completarse. No sólo porque la Constitución de Weimar es un documento especialmente típico del Estado constitucional burgués y porque su base ideológica encierra en sí misma las escisiones liberales entre Derecho y política, Derecho y fuerza, espíritu y fuerza, y de ahí en adelante, sino sobre todo porque ha eliminado totalmente la hegemonía prusiana, y así ha borrado completamente el último elemento directivo de la organización en Estado federal por lo demás mantenida. Es más: esta Constitución hacía decidir a un tribunal estatal de justicia, con procedimiento judicial, (art. 19) sobre la controversia en torno al Derecho federal hasta entre el Reich y los Länder, en vez de al consejo federal de antes; así proporcionaba a la

\footnotetext{
54 Heinrich Triepel, Die Reichsaufsicht. Untersuchungen zur Staatsrecht des Deutschen Reiches, Berlín, Springer 1917.
} 
aniquilación de la idea política de Jefe (Führer) y a todas las fuerzas destructoras del Reich interesadas en ello -tanto el pluralismo de los partidos políticos cuanto el particularismo de los Estados individualesuna nueva arma política, es decir la del proceso ante el Tribunal estatal de justicia. Entre los autores de la Constitución de Weimar hubo todavía muchos impedimentos contra estos métodos; y en la práctica estatal, con las crecientes dificultades de la situación política interna, debía imponerse cada vez más claramente la necesidad de la dirección política. Pero el normativismo dominante en la ciencia del Derecho del Estado de entonces y la falta de toda auténtica doctrina estatal colaboraron con celo para la judicialización ${ }^{55}$ de la política interior. Este estado de cosas también culminó en un concepto de superintendencia. Como última palabra de la vieja concepción de la superintendencia nació (en el ensayo de G. Heckel sobre la sentencia del tribunal de Estado de 25 de octubre de $1932^{56}$ ) la nueva acuñación: superintendencia de la Constitución. Después de que en el Derecho federal de la Constitución de Bismarck el concepto de "superintendencia del Reich" había sido un buen medio de relativización normativa de la dirección política, al final del sistema de Weimar se ha convertido en posible este concepto, visto todo con sentido normativista, de una "superintendencia" de la Constitución. En la expresión "superintendencia del Reich" resultaba al menos reconocible todavía el sujeto detentador de la superintendencia, el Reich; en otras formulaciones de conceptos, como superintendencia escolar, superintendencia municipal, se contiene al menos el sujeto sometido a la superintendencia.

En la expresión "superintendencia de la Constitución" no se revela en cambio ni el sujeto ni el objeto, sino sólo la medida en la que se basa la superintendencia, la Constitución. $Y$ este concepto, por lo demás bienintencionado, debía servir como base teórica para la facultad política decisiva de todo sistema federal, de ultima ratio de la unidad política de un Reich constituido como Estado federal, es decir de la Reichexekution! Con ello se había alcanzado el grado extremo de destrucción de la dirección política.

Tres momentos marcan la formación y el perfeccionamiento liberallegalista del concepto de superintendencia como un auténtico concepto antitético del principio de la dirección política. Primero, su tendencia normativista. Consiste en esto, que al concepto de la superintendencia se le conecta la representación de una medida para esta superintendencia, medida regulada previamente conforme al hecho, por tanto mensurable y verificable. A esta regla, predeterminada y por tanto que prescinde de toda situación concreta, se le someten todas las relaciones entre el superintendente y el vigilado. También los conceptos indeterminados e incluso los conceptos de criterio personal de semejante sistema de superintendencia se ven dominados por esta tendencia. También ellos deben encontrar su propio límite en el "exceso de criterio propio" y en el "abuso de criterio propio", es más un límite verificable por el juez. También la "prohibición de la arbitrariedad" que se incluye e interpreta en todas estas concepciones de superintendencia tiene el sentido político de

\footnotetext{
55 Nota del Traductor: "juridificación” dice Schmitt.

56 Johannes Heckel, Das Urteil des Staatsgerichtshofs vom 25.10.1932 in dem Verfassungsstreit Reich-Preussen,en "Archiv des öffentlichen Rechts”, vol 23, pag. 211.
} 
imponer la ficción de una mensurabilidad y predictibilidad con base en una norma precedente, y la corrección de todas las relaciones recíprocas de superintendencia.

La segunda nota característica de la formación de un concepto de superintendencia en contra del de dirección está en la tendencia a equiparar sujeto y objeto de la superintendencia. Resulta, sin más, con lógica coherencia a partir del normativismo que acabamos de recordar, implícito en su concepción de la superintendencia. Dado que la medida de la superintendencia, por lo que se dice, está ahí fija, calculable y verificable, se puede partir de la ficción de que ya previamente está determinado y fijado en qué medida quien detenta la superintendencia puede permitir "intromisiones" (esta palabra cargada de polémica política es característica de esta concepción, que dice ser puramente "jurídica"); cuánto deba tolerar el supervisado que se desconfíe de él; y por tanto el sometido puede siempre acogerse frente a la superintendencia a la norma como única medida decisiva. Entonces se ve que él en realidad no debe en absoluto estar sometido a la jerarquía que tiene la superintendencia y menos aún a un Jefe (Führer) político, sino siempre solamente al pretendido contenido normativo objetivo e impersonal, verificable por un tercero ajeno. $Y$ luego se ve que también el superintendente está sujeto a la misma norma y por consiguiente no se puede ya hablar de dirección y sumisión, sino por ambas partes sólo de interpretación "objetiva" de la norma y de delimitación "impersonal" de las competencias. Entonces también la palabra "superintendencia" está también equivocada y debe ser sustituida por "validez objetiva de las normas" y "aplicación de las normas".

La tercera propiedad de este concepto de superintendencia antitético al de mando se desarrolla, con la misma lógica, a partir de las dos características anteriores. $\mathrm{Si}$ tenemos ante nosotros una norma mensurable y ambas partes de la relación de superintendencia son equiparadas en su sometimiento a esta norma, es inevitable que sólo un tercero ajeno, igualmente "objetivo" - por tanto una instancia judicial independiente - se siente a juzgar por encima de ambas partes como órgano de esa norma objetiva. Tal concepto de superintendencia requiere ineludiblemente de una instancia judicial y la resolución procesal de todas las diferencias entre objeto de la superintendencia y superintendente. En todos los tipos, por lo demás entre sí tan diferentes, del concepto de superintendencia aparece por tanto al final una instancia judicial, que dice la última palabra en un procedimiento más o menos judicial. La idea de protección y aseguramiento esencialmente necesaria para la concepción liberal del Estado constitucional, transforma entonces, llevada hasta el final, a los tribunales administrativos por la decisión en controversias de Derecho sobre la superintendencia municipal, en autoridades para la superintendencia por encima de la superintendencia estatal; los tribunales punitivos del servicio, que, utilizando la jurisprudencia referente a los funcionarios, deben ser estrictos tribunales de clase, se transforman en simples dispositivos defensivos contra la regulación de la superintendencia del servicio, que deciden en lugar del superior sobre todas las posibilidades en la aplicación y sobre las actuaciones importantes de la supervisión del servicio; y el Tribunal de justicia estatal o constitucional se convierte en un órgano para la superintendencia política del gobierno, limitado a la superintendencia de la Constitución. El 
resultado siempre es administración de justicia en vez de dirección política. Un juez no es un Jefe (Führer) político, y los métodos para la controversia legal actual no son un modelo para un Estado legal de jefes. En el caso político decisivo la normativización y procesalización significa sólo una atadura del Jefe (Führer) para dar ventaja al desobediente; la equiparación de las partes significa sólo equiparación del enemigo del Estado y de la nación con el compañero del Estado y de la nación; la decisión mediante un juez independiente sólo significa la sumisión del Jefe (Führer) y del hombre del séquito a un no-jefe políticamente no responsable.

3. Guiar [führen] no es mandar [kommandieren], ser dictador no es gobernar de forma centralista-burocrática o cualquier especie de dominación [herrschen]. Hay muchas formas de dominio y mando, también de buen, justo y razonable dominio y poder de mando, que no son Führung. El dominio de los ingleses sobre la India y Egipto podrá justificarse con muchas razones, pero no es otra cosa que una dirección de los indios o de los egipcios por parte de los ingleses. La explotación de las colonias alemanas de una época por parte de las denominadas potencias mandatarias según el artículo 22 del estatuto de la Sociedad de Naciones se despacha con pretextos humanitarios para la "tutela" y la "educación", pero igualmente es dirección. Tampoco son dirección en nuestro sentido la mayor parte de los casos de dictaduras, que también pueden ser necesarias y saludables. También aquí tenemos que defendernos del peligro de que un concepto específicamente alemán y nacionalsocialista sea enturbiado y debilitado con una comparación con categorías extrañas.

Hay imágenes y comparaciones de muchos tipos que deben hacer evidente la relación de dominante y dominado, gobernante y gobernado, y me parece también jurídicamente más justo adquirir consciencia del significado objetivo de estas diferentes denominaciones que hablar, con la ayuda de las conocidas falsificaciones conceptuales, de una "especial relación de fuerza", que encuentra naturalmente su límite tanto en la norma preestablecida cuanto en la "vida privada". La iglesia católica romana por su poder de dominio sobre los creyentes ha transformado y completado la imagen del pastor y del rebaño en una idea teológicodogmática. Esencial en esta imagen es que el pastor permanece como absolutamente trascendente al rebaño. Éste no es nuestro concepto de "dirección". Una célebre cita de la "Política" de Platón trata de las diferentes comparaciones que se le presentan al hombre de Estado, con un médico, un pastor, o un piloto, para confirmar la imagen del piloto. Ha pasado mediante el "gobernator" a todas las lenguas influidas por el latín de los pueblos romances y anglosajones, y se ha convertido en la palabra para "gobierno" (Regierung) como gouvernement, governo, government, o como el "Gobernium" de la monarquía ausbúrgica de antes. La historia de este "gobernator" contiene un buen ejemplo de como una comparación imaginativa se convierte en un concepto jurídicotécnico. Otra imagen característica es la del caballo y el caballero, que el gran historiador francés Hipólito Taine utiliza para el señorío de Napoleón sobre el pueblo francés. Le cuadra fantásticamente a la figura imperial de este soldado italiano que se apoderó del Estado de la nación francesa, porque da la explicación más profunda de la necesidad interior en la que 
se encontraba este señorío: de normalizar precipitadamente hacia afuera y hacia adentro con éxitos militares continuamente nuevos y al mismo tiempo con nuevas legitimaciones (plebiscitos, coronación popular, matrimonio con una Asburgo) e institucionalizaciones (nueva nobleza).

Ninguna de estas imágenes recoge esencialmente lo que debe entenderse como dirección política (Führung) en el sentido esencialmente alemán de la palabra. Este concepto de dirección viene completamente del pensamiento concreto, sustancial, del movimiento nacionalsocialista. Es sintomático que cada imagen falle por mucho, y que cada imagen coincidente sea enseguida más que una imagen o que una comparación, sea de hecho dirección por sí misma. Nuestro concepto no necesita ni es capaz de una imagen que haga de intermediario o de comparación que la represente. No desciende ni de alegorías o de representaciones barrocas, ni de una idée générale cartesiana. Es un concepto del presente inmediato y de presencia real. Por esta razón implica también, como exigencia positiva, una absoluta igualdad de estirpe entre Jefe (Führer) y séquito. Sobre la igualdad de estirpe se fundamenta tanto el continuo e infalible contacto entre Jefe (Führer) y séquito cuanto su fidelidad recíproca. Sólo la igualdad de estirpe puede impedir que el poder del Jefe (Führer) se convierta en tiranía y arbitrariedad; sólo ella es la razón de la diferencia con cualquier dominio de una voluntad heterogénea, en cuanto que inteligente o ventajosa.

4. La igualdad de estirpe del pueblo alemán unido en sí mismo es por tanto el presupuesto y la base más indispensable para el concepto de dirección política del pueblo alemán. La idea de la raza en la Dieta nacionalsocialista alemana de juristas, en Leipzig en 1933, fue resituada en el centro, en el potente discurso de cierre del Jefe (Führer), en la movilizadoras alocuciones del Jefe (Führer) del Frente Jurídico Alemán, el Dr. G. Franck, y en excelentes redacciones de especialistas, como especialmente en la conferencia de E. Nicolai y no se trata de un postulado obtenido de forma abstracta. Sin el principio de la identidad de estirpe el Estado nacionalsocialista no podría resistir, y su vida jurídica no sería imaginable; caería enseguida en manos, junto con todas sus instituciones, de sus enemigos liberales o marxistas -que ahora critican con aires de superioridad, ahora se aproximan servilmente.

Para el jurista científico del nuevo Derecho alemán es especialmente necesario tomar consciencia de la energía sistemática de este concepto de igualdad de estirpe, fuerza que compenetra a todas las consideraciones jurídicas. La ficción del vínculo normativista del juez a una ley se ha convertido hoy teórica y prácticamente en insostenible para muchas esferas esenciales de la vida jurídica práctica. La ley ya no puede de hecho encontrar la previsibilidad y la seguridad que para la concepción constitucional pertenecen a la misma definición de la ley. La seguridad y previsibilidad no están en la norma, sino en la situación que se presume como "normal". Desde todas partes y con innumerables circunloquios han penetrado en todos los campos de la vida jurídica, incluso en el Derecho penal, las denominadas cláusulas generales y conceptos indeterminados: "fidelidad y fe", "buenas costumbres", "motivo importante", "dureza injusta", "sospechoso", "especial necesidad", "ventaja desproporcionada", "intereses preponderantes", "derecho de 
abuso", "derecho de arbitraje" intereses",- estos son sólo algunos ejemplos de esta indefinición de un normativismo legalista. Tales cláusulas generales se han convertido desde hace mucho tiempo en inevitables e indispensables, y determinan internamente el cuadro general de nuestra administración de justicia tanto de Derecho privado como de Derecho público. Un escrito aparecido recientemente (1933) del profesor de Derecho Hedemann, de Jena, La invocación excesiva de las cláusulas generales, nos transmite una viva fotografía de la enorme difusión de estas cláusulas; pone en guardia con palabras serias contra el peligro de una completa disolución del Derecho en generalidades normativamente indeterminadas e incalculables. Pero yo no creo que el gran problema de las cláusulas generales se haya resuelto con esto. La disolución e intermediación de todos los conceptos, especialmente ante lo que hoy se escribe en todas las disciplinas jurídicas, me parece que ha avanzado mucho más de lo que Hedemann dice. Incluso "efectivo" y "posesión directa" pudieron ser reconocidos como conceptos indeterminados, no por un talmudista cualquiera sino por un respetable profesor de Derecho alemán, Felipe Heck, de Tubinga. En la teoría y en la praxis jurídica no hemos llegado todavía a plantear con toda seriedad práctica la cuestión gnoseológica: hasta qué punto una palabra o un concepto del legislador pueden en general vincular de forma verdaderamente predecible a los hombres que aplican la ley. Nosotros hemos vivido la experiencia de que toda palabra y todo concepto se conviertan enseguida en controvertido, inseguro, indeterminado y oscilante, si en una situación dudosa se apoderan de ellos espíritus e intereses de diverso tipo. En especial todo nuestro Derecho administrativo está dominado por tales conceptos indeterminados, no ligados a una norma sino a una situación (como "seguridad y orden público", "peligro", "estado de necesidad", "proporcionalidad", etc.), y también conceptos como: "iniciativa debida", "discrecionalidad" y "prohibición de discrecionalidad" son en caso de conflicto casi impredecibles, pudiendo convertirse ellos mismos en la peor discrecionalidad.

Desde este punto de vista, hoy sólo hay conceptos jurídicos "indeterminados". Que hoy fuese posible volver a la antigua fe en una regulación legal de todos los casos posibles, a medida por adelantado y para hechos, sin lagunas, y predecible con seguridad, nadie querrá afirmarlo. La ficción e ilusión de una ley que abarque por adelantado todos los casos y todas las situaciones conforme a los hechos y mediante su subsunción, no se puede ya resucitar, es más la idea de un intento de codificación y de regulación sin lagunas es hoy difícil de imaginar. "Sobre volver atrás al riguroso positivismo no cabe ni siquiera plantearlo", dice también F. Heck con buen criterio (Jur. Woch., 1933, p. 1449). Así la aplicación de las leyes está entre Escila y Caribdis. Ese camino parece conducir a un mar sin orillas y a alejarse cada vez más de la tierra firme de la seguridad jurídica y de la adhesión a la ley, que también es al mismo tiempo el terreno de la independencia de los jueces; el camino inverso, hacia una formalista superstición de la ley que se ha reconocido sin sentido e históricamente superada desde hace mucho tiempo, no es tampoco merecedor de consideración.

\footnotetext{
${ }^{57}$ Nota del Traductor: debe entender como "discrecionalidad" y "arbitrariedad", pero no es esa la expresión utilizada por el traductor italiano
} 
Aquí sólo hay una vía: el Estado nacionalsocialista la ha tomado con gran seguridad, y el secretario de Estado Freisler le ha otorgado la más clara señal diferenciadora estableciendo esta exigencia: "no reforma de la justicia, sino reforma de los juristas". Si una administración de justicia independiente debe seguir existiendo y una adhesión mecánica y automática del juez a normas preestablecidas no es posible, entonces todo depende precisamente de la especie y la tipología de jueces y funcionarios. Nunca la cuestión quis iudicabit ha tenido una importancia tan decisiva para todo como hoy. $\mathrm{Ni}$ siquiera en el sistema liberaldemócrata han faltado exigencias éticas y morales, dirigidas a la "personalidad creativa" del juez.

Pero esto quedaba en una declamación vacía, porque se hablaba solamente de "personalidad" en general, y la palabra, al servicio de un individualismo liberal, tenía como objetivo solamente al "hombre" y al pueblo alemán concreto (para no tener que distinguir entre igual de estirpe y extraño a la estirpe). Con toda resolución debe garantizarse la auténtica y propia sustancia de la "personalidad" y ésta está en la exigencia de que cada hombre encargado de la exposición, interpretación y aplicación del Derecho alemán esté vinculado a la nación, al pueblo, por igualdad de estirpe. Desde las necesidades positivas del trabajo jurídico la idea de la igualdad de estirpe atravesará y dominará todo nuestro Derecho público. Vale tanto para la clase de los funcionarios de carrera, como para aquélla, esencialmente interesada en la creación y la configuración del Derecho, de los abogados, como para todos los casos en los que connacionales pasen a ser activos en la administración, en la justicia y en la teoría jurídica. Garantizará ante todo también en la composición de los diversos nuevos "consejos de Jefes" una fecunda colaboración.

Sabemos no sólo por sentimientos, sino en base al más riguroso conocimiento científico, que todo Derecho es el Derecho de un pueblo determinado. Es una verdad gnoseológica que está en situación de ver bien los hechos, de escuchar bien las declaraciones, de entender bien las palabras y de valorar justamente las impresiones de los hombres y de las cosas sólo aquél que forme parte de la colectividad creadora del Derecho de una forma esencial y determinada por la estirpe, y que pertenezca a ella esencialmente. El hombre se encuentra en la realidad de esta pertenencia a un pueblo y a una raza hasta en los más profundos e inconscientes impulsos del ánimo, y también hasta la más pequeña fibra cerebral. No es objetivo quien quiera que quisiese serlo ni quien quiera que crea subjetivamente de buena fe que ha trabajado lo bastante para serlo. Un extraño a la estirpe puede situarse en la crítica y afanarse sagazmente cuanto quiera, puede leer libros y escribir libros; pero él piensa y entiende de forma distinta, porque él está hecho de otra manera, y permanece, para todo orden esencial de ideas, en las condiciones existenciales de su propia naturaleza. Ésta es la realidad objetiva de la "objetividad".

Cuando se podía tener fe en que juez, y también funcionario de la administración fuese sólo una función de la legalidad normativista, solamente la conocida "autónoma aplicación de la ley", una simple "concreción de normas abstractas", se podía obviar esta verdad, que todo 
pensamiento humano está vinculado al ser, así como está vinculada a la situación cada norma y cada concreción de un hecho. La célebre frase de Montesquieu, que el juez es "sólo la boca que pronuncia las palabras de la ley", "la bouche, qui prononce les paroles de la loi", del siglo XVIII generalmente fue entendida mecánicamente. Para nuestra forma de sentir actual esta frase conduce ya a la esfera del ser humano vivo lleno de diferencias orgánicas, biológicas y de raza. Hoy nos hemos hecho más sensibles; nosotros vemos la diversidad también en las bocas, si lo puedo decir así, que dicen las palabras y las frases que pretenderían ser iguales. Nosotros oímos como ellas "pronuncian" las mismas palabras de forma muy distinta. Nosotros sabemos que la misma palabra en la boca de diferentes pueblos no sólo suena de forma distinta, sino que significa algo distinto en el sentido y en la cosa, y que en cuestiones de interpretación de una ley y de la relevancia de un hecho, pequeñas diferencias tienen a la larga efectos sorprendentes. No obstante esto debemos y queremos conservar tanto la posición legalmente garantizada del funcionario alemán, como especialmente la independencia de los jueces. Por ello nosotros demandamos la necesidad de aquellos vínculos, sin los cuales todas las garantías y libertades, toda independencia de los jueces y antes que nada también aquella "creatividad", serían sólo anarquía y una fuente particularmente perversa de peligros políticos. Nosotros buscamos un vínculo que sea más respetable, más vivo y más profundo que el engañoso vínculo con la letra manipulable de mil parágrafos de leyes. ¿Dónde podría estar sino en nosotros mismos y en nuestra propia estirpe? También aquí, ante la conexión inseparable del vínculo legal, funcionario e independencia del juez, todos los interrogantes y las soluciones desembocan en la exigencia de una igualdad de estirpe sin la cual un Estado total de jefes no puede subsistir ni un solo día. 